\title{
Increased expression of interleukin-6 family members and receptors in urinary bladder with cyclophosphamide-induced bladder inflammation in female rats
}

\author{
Beatrice M. Girard ${ }^{1}$, Bopaiah P. Cheppudira ${ }^{2}$, Susan E. Malley ${ }^{2}$, Kristin C. Schutz $^{1}$, Victor May' and \\ Margaret A. Vizzard ${ }^{1,2 *}$
}

1 Department of Anatomy and Neurobiology, University of Vermont College of Medicine, Burlington, VT, USA

2 Department of Neurology, University of Vermont College of Medicine, Burlington, VT, USA

\section{Edited by:}

Thomas Chelimsky, Case Western

Reserve University, USA

\section{Reviewed by:}

Stuart M. Brierley, Hanson Institute, Australia

Dale E. Bjorling, University of

Wisconsin-Madison Medical School, USA

\section{*Correspondence:}

Margaret A. Vizzard, Department of Neurology, University of Vermont College of Medicine, D415A Given Research Building, Burlington, VT 05405, USA.

e-mail:margaret.vizzard@uvm.edu
Recent studies suggest that janus-activated kinases-signal transducer and activator of transcription signaling pathways contribute to increased voiding frequency and referred pain of cyclophosphamide (CYP)-induced cystitis in rats. Potential upstream chemical mediator(s) that may be activated by CYP-induced cystitis to stimulate JAK/STAT signaling are not known in detail. In these studies, members of the interleukin (IL)-6 family of cytokines including, leukemia inhibitory factor (LIF), IL-6, and ciliary neurotrophic factor (CNTF) and associated receptors, IL-6 receptor (R) $\alpha$, LIFR, and gp130 were examined in the urinary bladder in control and CYP-treated rats. Cytokine and receptor transcript and protein expression and distribution were determined in urinary bladder after CYP-induced cystitis using quantitative, real-time polymerase chain reaction (Q-PCR), western blotting, and immunohistochemistry. Acute (4 h; 150 mg/kg; i.p.), intermediate (48 h; $150 \mathrm{mg} / \mathrm{kg}$; i.p.), or chronic (75 mg/kg; i.p., once every 3 days for 10 days) cystitis was induced in adult, female Wistar rats with CYP treatment. Q-PCR analyses revealed significant ( $p \leq 0.01$ ) CYP duration- and tissue- (e.g., urothelium, detrusor) dependent increases in LIF, IL-6, IL-6R $\alpha$, LIFR, and gp130 mRNA expression. Western blotting demonstrated significant $(p \leq 0.01)$ increases in IL-6, LIF, and gp130 protein expression in whole urinary bladder with CYP treatment. CYP-induced cystitis significantly $(p \leq 0.01)$ increased LIF-immunoreactivity (IR) in urothelium, detrusor, and suburothelial plexus whereas increased gp130-IR was only observed in urothelium and detrusor. These studies suggest that IL-6 and LIF may be potential upstream chemical mediators that activate JAK/STAT signaling in urinary bladder pathways.

Keywords: urothelium, detrusor smooth muscle, Q-PCR, Western blotting, gp130, LIF

\section{INTRODUCTION}

Cytokine receptors signal predominantly through janus-activated kinases (JAK)-signal transducer and activator of transcription (STAT) pathways (Dziennis and Alkayed, 2008) and we recently demonstrated that cyclophosphamide (CYP)-induced cystitis of varying duration was associated with enhanced JAK-STAT signaling (Cheppudira et al., 2009). STAT3 phosphorylation/activation was increased after CYP-induced cystitis $(4 \mathrm{~h}, 48 \mathrm{~h}$, and chronic; Cheppudira et al., 2009). Functionally, blockade of JAK2 with AG490, a member of the tyrphostin family of tyrosine kinase inhibitors, significantly reduced bladder hyperreflexia and hind paw sensitivity in CYP-treated rats (Cheppudira et al., 2009). In aggregate, these studies demonstrated potential roles for JAK-STAT signaling pathways in contributing to bladder hyperreflexia and referred pain of CYP-induced bladder inflammation (Cheppudira et al., 2009). However, is not known what is/are the upstream chemical mediator(s) that are activated by CYP-induced cystitis to stimulate JAK/STAT signaling.

Bladder pain syndrome (BPS)/interstitial cystitis (IC) is viewed as a one type of chronic pain syndrome characterized by pain, pressure, or discomfort perceived to be bladder related with at least one urinary symptom such as urinary frequency (Hanno et al., 2010).
Although the etiology and pathogenesis of BPS/IC are unknown, numerous theories including; infection, inflammation, autoimmune disorder, toxic urinary agents, urothelial dysfunction, and neurogenic causes have been proposed (Petrone et al., 1995; Ho et al., 1997; Johansson et al., 1997; Driscoll and Teichman, 2001; Sant and Hanno, 2001). We have hypothesized that pain associated with BPS/IC involves an alteration of visceral sensation/bladder sensory physiology. Altered visceral sensations from the urinary bladder (i.e., pain at low or moderate bladder filling) that accompany BPS/IC (Petrone et al., 1995; Ho et al., 1997; Johansson et al., 1997; Driscoll and Teichman, 2001; Sant and Hanno, 2001) may be mediated by many factors including changes in the properties of peripheral bladder afferent pathways such that bladder afferent neurons respond in an exaggerated manner to normally innocuous stimuli (allodynia). These changes may be mediated, in part, by inflammatory changes in the urinary bladder. Among potential mediators of inflammation, neurotrophins (e.g., nerve growth factor) have been implicated in the peripheral sensitization of nociceptors (Lindsay and Harmar, 1989; Dray, 1995; Dinarello, 1997). Pro-inflammatory cytokines also cause sensitization of polymodal C-fibers (Dray, 1995) and facilitate A-beta input to the spinal cord (Woolf and Doubell, 1994; Baba et al., 1999). Several studies 
from our laboratory have demonstrated increased cytokine and chemokine expression and beneficial effects of chemokine receptor blockade in the urinary bladder after CYP-induced bladder inflammation (Malley and Vizzard, 2002). Furthermore, a recent study has also demonstrated upregulation of interleukin (IL)-6 transcript and protein expression in the submucosal layer of bladder after CYP treatment in mice (Nishii et al., 2006). In addition, lipopolysaccharide, IL-1 $\beta$, and tumor necrosis factor (TNF)- $\alpha$ induce production and/or secretion of IL- 6 and IL- 6 receptor (R) $\alpha$ in cultured, human detrusor smooth muscle cells (Bouchelouche et al., 2006; Neuhaus et al., 2007).

The IL- 6 family of cytokines, through receptor interactions, induce transphosphorylation of the receptor-associated JAK, which in turn leads to phosphorylation of the down-stream STAT family of transcription factors (JAK-STAT pathway; Dziennis and Alkayed, 2008). The IL-6 family of cytokines also activates mitogen-activated protein kinase (MAPK) signaling pathways and associated transcription factors (Gadient and Patterson, 1999). Among the IL-6 family, leukemia inhibitory factor (LIF) is a multifunctional polypeptide cytokine/growth factor, related in both structure and mechanisms of action to the IL-6 family of cytokines (Knight, 2001). LIF is involved in neuronal developmental processes including neurogenesis, differentiation, and survival (Kim et al., 2005). Numerous studies have also demonstrated elevated LIF in a variety of inflammatory conditions in humans and other animals (Alexander et al., 1994). Some reports suggest that LIF acts as a pro-inflammatory mediator (Sugiura et al., 2000), whereas other evidence indicates LIF functions as an anti-inflammatory and analgesic cytokine (Ulich et al., 1994; Banner et al., 1998). The closely related pleiotropic cytokine, IL-6, has numerous biological activities and is generally considered to be pro-inflammatory. The diverse biological activities of IL-6 include promotion of neuronal survival, protection against neuronal damage, induction of neuronal differentiation, modulation of neurotransmitter/neuromodulator synthesis, and modulation of pain. Receptors involved in the recognition of LIF and IL- 6 include the non-signaling $\alpha$-receptors, IL-6R $\alpha$, and the transducing receptors, gp130, and LIFR with gp130 being used by all IL-6 family members in different combinations (Hibi et al., 1990).

The purpose of this study was to determine potential upstream chemical mediator(s) that may be activated by CYP-induced cystitis to stimulate JAK/STAT signaling. Among the IL-6 family of cytokines, we have focused the current study on the urinary bladder expression and changes in transcript and protein expression of IL- 6 and LIF and associated receptors, IL-6R $\alpha$, LIFR, and gp130 with CYP-induced cystitis of varying duration. The CYP rodent model exhibits urinary bladder dysfunction (Hu et al., 2003, 2005; Klinger and Vizzard, 2008; Arms et al., 2010) and altered somatic sensitivity (Guerios et al., 2008; Studeny et al., 2008; Cheppudira et al., 2009) and permits a controlled analysis of some aspects of BPS/IC that are not feasible to address in the human population. Use of the CYP rat model is one way to examine the contribution of inflammatory and immune mediators to urinary bladder dysfunction and referred somatic sensitivity exhibited in the human syndrome of BPS/IC. A variety of techniques including immunohistochemistry in urinary bladder tissue sections and whole mounts with semiquantitation, quantitative real-time polymerase chain reaction (Q-PCR), and Western blotting approaches were used.

\section{MATERIALS AND METHODS ANIMALS}

Adult female, Wistar rats (200-225 g; Charles River, St. Constant, Canada) were used for this study. Rats were housed two per cage and maintained in standard laboratory conditions with free access to food and water. The University of Vermont Institutional Animal Care and Use Committee approved all animal use procedures (protocol 08-085).

\section{INDUCTION OF CYCLOPHOSPHAMIDE-INDUCED CYSTITIS}

Rats were anesthetized under isoflurane (2\%) and acute cystitis was induced with a single injection of CYP $(150 \mathrm{mg} / \mathrm{kg}$, i.p. $)$ and rodents were used in studies at various time points ( 4 or $48 \mathrm{~h}$ ) after treatment (Cheppudira et al., 2008; Klinger and Vizzard, 2008; Klinger et al., 2008). Chronic CYP-cystitis was induced by administration of CYP ( $75 \mathrm{mg} / \mathrm{kg}$; i.p.) once every 3 days for 8 days (Cheppudira et al., 2008; Klinger and Vizzard, 2008; Klinger et al., 2008). Control rodents received either saline injection or no treatment. Rats were euthanized using isoflurane (5\%) and a thoracotomy.

\section{REAL-TIME QUANTITATIVE REVERSE TRANSCRIPTION-POLYMERASE CHAIN REACTION (0-PCR)}

Total RNA was extracted using the STAT-60 total RNA/mRNA isolation reagent (Tel-Test"B," Friendswood, TX, USA) as previously described (Girard et al., 2002; Klinger et al., 2008; Arms et al., 2010). One to $2 \mathrm{mg}$ of RNA per sample was used to synthesize complementary DNA using a mix of random hexamer and oligo dT primers with M-MLV reverse transcriptase (Promega Corp.) in a $25-\mu \mathrm{l}$ final reaction volume.

The quantitative PCR standards for all transcripts were prepared with the amplified IL-6, LIF, CNTF, gp130, IL-6R $\alpha$, LIFR cDNA products ligated directly into $\mathrm{PCR} 2.1 \mathrm{TOPO}$ vector using the TOPO TA cloning kit (Invitrogen). The nucleotide sequences of the inserts were verified by automated fluorescent dideoxy dye terminator sequencing (Vermont Cancer Center DNA Analysis Facility). To estimate the relative expression of the receptor transcripts, 10 -fold serial dilutions of stock plasmids were prepared as quantitative standards. The range of standard concentrations was determined empirically.

Complementary DNA templates, diluted 10-fold to minimize the inhibitory effects of the reverse transcription reaction components, were assayed using HotStart-IT SYBR Green qPCR Master Mix (USB, Cleveland, $\mathrm{OH}, \mathrm{USA}$ ) and $300 \mathrm{nM}$ of each primer in a final $25 \mu$ reaction volume (Girard et al., 2002; Klinger et al., 2008; Arms et al., 2010). The real-time quantitative PCR was performed (Applied Biosystems 7500 Fast real-time PCR system, Foster City, CA, USA; Girard et al., 2002; Klinger et al., 2008; Arms et al., 2010) using the following standard conditions: (i) serial heating at $94^{\circ} \mathrm{C}$ for $2 \mathrm{~min}$; (ii) amplification over 40 cycles at $94^{\circ} \mathrm{C}$ for $15 \mathrm{~s}$ and $60-64^{\circ} \mathrm{C}$ depending on primer sets for $30 \mathrm{~s}$.

The amplified product from these amplification parameters was subjected to SYBR Green I melting analysis by ramping the temperature of the reaction samples from 60 to $95^{\circ} \mathrm{C}$. A single DNA melting profile was observed under these dissociation assay conditions demonstrating amplification of a single unique product free of primer dimers or other anomalous products. The primer sequences used are described in Table 1. 
Table 1 | Primer sequences.

\begin{tabular}{|c|c|c|}
\hline Name & Location & Sequence \\
\hline Rat IL-6 & $99 \cup 20$ & TTGCCTTCTTGGGACTGATG \\
\hline Rat IL-6 & 261L20 & GCCATTGCACAACTCTTTTC \\
\hline IL-6R $\alpha$ & $29 \cup 20$ & AGCCAGTTGCCTTCTTGGGA \\
\hline IL-6R $\alpha$ & 188L25 & TTGCACAACTCTTTСТСАТTTCCA \\
\hline Rat LIF & $179 \cup 25$ & ATGCССТСTTTATTTCCTATTACAC \\
\hline Rat LIF & 408L25 & CATGACGTCTGTAGTCGCATTGAGT \\
\hline LIFR & $124 \cup 23$ & AATGGTCTTAAGAGAGGGGTACA \\
\hline LIFR & 215L20 & TTTAACAGTTCCAGGGCTGA \\
\hline gp130 & $1954 \cup 20$ & ACCCCCCAAGGCACAATTTTA \\
\hline gp130 & $2549\llcorner 24$ & АCCTGCTGCTGTTTCAGTCTGACA \\
\hline Rat CNTF & $3 \cup 21$ & TCACATTTCTTATTTGGACTA \\
\hline Rat CNTF & $662\llcorner 21$ & GGCTACATCTGCTTATCTTTG \\
\hline L32 & $83 \cup 20$ & CCTGGCGTTGGGATTGGTGA \\
\hline L32 & 129L20 & GAAAAGCCATCGTAGAAAGA \\
\hline
\end{tabular}

Primer names, locations, and sequences used in this study. Location of the primers corresponds to following coding sequences: MN_012589, MN_017020, MN_022196, MN_031048, MN_001008725, MN_013166, XM_001056774. IL, interleukin; $R$, receptor; LIF, leukemia inhibitory factor; CNTF, ciliary neurotrophic factor.

For data analyses, a standard curve was constructed by amplification of serially diluted plasmids containing the target sequence. Data were analyzed at the termination of each assay using sequence detection software (Sequence Detection Software, version 1.3.1; Applied Biosystems, Norwalk, CT, USA). In standard assays, default baseline settings were selected. The increase in SYBR Green I fluorescence intensity $(\Delta \mathrm{Rn})$ was plotted as a function of cycle number and the threshold cycle was determined by the software as the amplification cycle at which the $\Delta \mathrm{Rn}$ first intersects the established baseline. All urothelium and detrusor data were normalized to housekeeping gene L32 transcript expression in the same cDNA templates (Table 1). Transcript levels in treated urothelium samples were expressed relative to control urothelium levels. To allow ease of transcript level comparisons between different tissues, the normalized transcript levels in detrusor were expressed as a function of normalized control urothelium Q-PCR data.

\section{SPLIT BLADDER PREPARATION AND ASSESSMENT OF POTENTIAL CONTAMINATION OF BLADDER LAYERS}

The urothelium + suburothelium was dissected from the detrusor smooth muscle using fine forceps under a dissecting microscope as previously described (Zvarova and Vizzard, 2005; Cheppudira et al., 2008; Klinger et al., 2008). To confirm the specificity of our split bladder preparations, urothelium + suburothelium and detrusor samples were examined for the presence of $\alpha$-smooth muscle actin (1:1000; Abcam, Cambridge, MA, USA) and uroplakin II (1:25; American Research Products, Belmont, MA, USA) by Western blotting or reverse transcription PCR (Corrow and Vizzard, 2007; Cheppudira et al., 2008). In urothelium + suburothelium layers, only uroplakin II was present (data not shown). Conversely, in detrusor samples, only $\alpha$-smooth muscle actin was present (data not shown).

\section{WESTERN BLOTTING FOR IL-6, LIF, GP130 EXPRESSION IN WHOLE URINARY BLADDER}

Whole urinary bladders (control, $4 \mathrm{~h}, 48 \mathrm{~h}$, and chronic; $n=6$ ) were homogenized separately in tissue protein extraction agent (T-PER; Roche, Indianapolis, IN, USA), a mild zwitterionic dialyzable detergent in $25 \mathrm{mM}$ bicine, $150 \mathrm{mM}$ sodium chloride ( $\mathrm{pH}$ 7.6) containing a protease inhibitor mix (Sigma-Aldrich, St. Louis, MO, USA; $16 \mu \mathrm{g} / \mathrm{ml}$ benzamidine, $2 \mu \mathrm{g} / \mathrm{ml}$ leupeptin, $50 \mu \mathrm{g} / \mathrm{ml}$ lima bean trypsin inhibitor, and $2 \mu \mathrm{g} / \mathrm{ml}$ pepstatin A) and aliquots were removed for protein assay. Samples $(25 \mu \mathrm{g})$ were suspended in sample buffer for fractionation on gels and subjected to SDS-PAGE. Proteins were transferred to nitrocellulose membranes, and efficiency of transfer was evaluated. Membranes were blocked overnight in a solution of $5 \%$ milk, $3 \%$ bovine serum albumin in Tris-buffered saline with $0.1 \%$ Tween. For immunodetection, the following antibodies were used overnight at $4^{\circ} \mathrm{C}$ : goat anti-LIF [1:200; Santa Cruz Biotechnology, Inc., Santa Cruz, CA, USA (catalog \#SC1336)], rabbit anti-gp130 (1:1000; Santa Cruz Biotechnology, Inc. (catalog \#SC655), and rabbit anti-IL-6 (1:1000; Invitrogen Corporation, Carlsbad, CA, USA (catalog \#ASC0062). Washed membranes were incubated in species-specific secondary antibodies for $2 \mathrm{~h}$ at room temperature for enhanced chemiluminescence detection (Pierce, Rockford, IL, USA). Blots were exposed to Biomax film (Kodak, Rochester, NY, USA) and developed. The intensity of each band was analyzed, and background intensities were subtracted using Un-Scan It software (Silk Scientific, Orem, UT, USA). Western blot analysis of actin (1:2000; Santa Cruz Biotechnology (catalog \#SC1616R) in samples was used as a loading control. In this and previous studies (Corrow et al., 2010), we have used actin as a loading control as expression of actin protein was not changed in urinary bladder with CYP treatments.

\section{IMMUNOHISTOCHEMICAL LOCALIZATION OF LIF, IL-6, GP130 IN UROTHELIUM}

The bladders from control, acute $(4 \mathrm{~h})$, intermediate $(48 \mathrm{~h})$, and chronic CYP-treated rats $(n=6$ for each) were rapidly dissected, weighed, post-fixed in $4 \%$ paraformaldehyde, and placed in ascending concentrations of sucrose (10-30\%) in $0.1 \mathrm{M}$ PBS for cryoprotection. Cryostat sections $(20 \mu \mathrm{m})$ of urinary bladder were mounted on gelled $(0.5 \%)$ microscope slides for on-slide processing as previously described (Yuridullah et al., 2006; Corrow and Vizzard, 2007; Cheppudira et al., 2008; Klinger and Vizzard, 2008; Klinger et al., 2008). Briefly, sections were incubated with $400 \mu$ l of goat anti-LIF [1:500; Santa Cruz Biotechnology, Inc. (SC1336)], rabbit anti-gp130 [1:1000; Santa Cruz Biotechnology, Inc. (catalog \#SC655) or rabbit anti-IL-6 (1:200-1:5000; Invitrogen Corporation (catalog \#ASC0062; \#ARC0062); Santa Cruz (1:200$1: 3000$; catalog \#1265)] in $1 \%$ donkey or goat serum and $0.1 \mathrm{M}$ phosphate-buffer overnight at room temperature. After washing $(3 \times 10 \mathrm{~min})$ with $0.1 \mathrm{M}$ PBS $(\mathrm{pH} 7.4)$ the tissues were incubated with Cy3-conjugated species-specific antibodies (1:500; Jackson Immunoresearch Laboratories, West Grove, PA, USA) for $2 \mathrm{~h}$ at room temperature, rinsed and mounted with antifade medium (Citifluor, Fisher Scientific, Pittsburgh, PA, USA) for fluorescence microscopy. Control sections incubated in the absence of primary or secondary antibody were also processed and evaluated for specificity or background staining levels. In the absence of primary antibody, no positive immunostaining was observed. Immunoabsorptions with LIF and gp130 peptide $(5 \mu \mathrm{g} / \mathrm{ml}$; Santa Cruz) and antisera in bladder sections resulted in no staining above background. Repeated attempts to localize IL-6-immunoreactivity (IR) in cryostat bladder sections with different antibodies and 
substantial trouble-shooting were not successful. Thus, data are not presented for immunohistochemical localization of IL-6-IR in urinary bladder.

\section{VISUALIZATION AND SEMI-QUANTITATIVE ANALYSIS OF LIF-, GP130-IR IN URINARY BLADDER \\ Urothelium}

Leukemia inhibitory factor- and gp130-IR in bladder sections from control $(n=6)$ and CYP-treated groups ( $n=6$ each) was visualized and images were captured using an Olympus fluorescence photomicroscope. The filter was set with an excitation range of 560-569 nm and emission range of 610-655 $\mathrm{nm}$ for visualization of Cy3. Images were captured, acquired in tagged image file format and imported into image analysis software (Meta Morph, version 4.5r4, University Imaging, Downingtown, PA, USA; (Klinger et al., 2008; Arms et al., 2010). The free hand drawing tool was used to select the urothelium and the urothelium was measured in total pixels area as previously described (Klinger et al., 2008; Arms et al., 2010). A threshold encompassing an intensity range of 100-250 grayscale values was applied to the region of interest in the least brightly stained condition first. The threshold was adjusted for each experimental series using concomitantly processed negative controls as a guide for setting background fluorescence. The same threshold was subsequently used for all images. IR was considered to be positive only when the staining for the marker of interest (LIF, gp130) exceeded the established threshold. Percent marker expression above threshold in the total area selected was calculated. LIF- and gp130-IR in the urothelium was consistent across all regions (dome, body, neck) of the urinary bladder examined for all conditions. Semi-quantification of LIF and gp130 expression in the urothelium is presented for the bladder neck region.

\section{Detrusor smooth muscle}

Visualization of LIF- and gp130-IR in detrusor smooth muscle of cryostat sections from control $(n=6)$ and CYP-treated groups $(n=6$ each) was identical to that described for the urothelium (above). Semi-quantification of IR in detrusor smooth muscle was performed as previously described (Klinger et al., 2007; Cheppudira et al., 2008) and modified from Brady et al. (2004). Grayscale images acquired in tagged image file format were imported into image analysis software (Image J; Abramoff et al., 2004) and images were thresholded. Images of detrusor smooth muscle were acquired from the dome, body, and neck region of the urinary bladder in control and CYP treatment groups. A rectangle of fixed dimension $(500 \times 500$ pixels $)$ was placed on the section according to a random selection of $x$ and $y$ coordinates. This process was repeated seven times for each image of detrusor. The average optical density of LIF or gp130 expression in detrusor smooth muscle was then calculated. Expression of LIF or gp130 examined in the detrusor exhibited equivocal expression throughout detrusor of the dome, body, and neck of the urinary bladder; thus, data from each region are pooled and presented as LIF or gp130-IR above threshold in detrusor smooth muscle.

\section{Suburothelial nerve plexus in urinary bladder whole mounts}

The urinarybladder from control $(n=6)$ and experimental treatments ( $n=6$ each) was dissected and placed in Krebs solution. The bladder was cut open along the midline and pinned to a sylgard-coated dish. While pinned, the bladder neck on one side was notched for orienta- tion purposes and regional analyses of IR. The bladder was incubated for $1.5 \mathrm{~h}$ at room temperature in cold fixative (2\% paraformaldehyde $+0.2 \%$ picric acid). Using fine tips forceps and iris scissors, the urothelium + suburothelium was dissected from the underlying detrusor smooth muscle with the aid of a dissecting microscope (Corrow and Vizzard, 2007; Klinger and Vizzard, 2008). Urothelium + suburothelium and bladder musculature were processed for LIF- or gp130-IR (as described above). No gp130-IR was observed in the suburothelial nerve plexus from control or experimental treatments (data not shown). In some whole mounts processed for LIF-IR, nerve fibers in the suburothelial nerve plexus were also stained with the pan neuronal marker, protein gene product (PGP 9.5; Abcam, Cambridge, MA, USA; 1:15). After washing $(3 \times 10 \mathrm{~min})$ with $0.1 \mathrm{M} \mathrm{PBS}(\mathrm{pH} 7.4)$ the tissues were incubated with a cocktail of Cy3-conjugated donkey anti-goat (1:500) and Cy2-conjugated donkey anti-rabbit secondary antibody for $2 \mathrm{~h}$ at room temperature. After washing, the whole mounts were placed on microscope slides and coverslipped and were examined under an Olympus fluorescence photomicroscope as described above. Cy2 was visualized with a filter with an excitation range of 470-490 and an emission range from 510 to 530 .

\section{ASSESSMENT OF IMMUNOHISTOCHEMICAL STAINING IN URINARY BLADDER REGIONS}

Immunohistochemistry and subsequent semi-quantification of LIFor gp130-IR in bladder sections or whole mount preparations was performed on control and experimental tissues simultaneously to reduce the incidence of staining variation that can occur between tissues processed on different days. Staining observed in experimental tissue was compared to that observed from experiment-matched negative controls. Urinary bladder sections or whole mounts exhibiting IR that was greater than the background level observed in experimentmatched negative controls were considered positively stained.

\section{FIGURE PREPARATION}

Digital images were obtained using a CCD camera (MagnaFire SP; Optronics; Optical Analysis Corp., Nashua, NH, USA) and LG-3 frame grabber (Scion Corp; Frederick, MD, USA). Exposure times, brightness and contrast were held constant when acquiring images from experimental or control animals processed and analyzed on the same day. Images were imported into a graphics-editing program (Adobe Photoshop 7.0, Adobe Systems Incorporated, San Jose, CA, USA) assembled and labeled.

\section{STATISTICS}

All values are mean \pm SEM. Data were compared using ANOVA. Percentage data from image analysis were arcsin transformed to meet the requirements of this statistical test. Animals, processed and analyzed on the same day, were tested as a block in the ANOVA. When $\mathrm{F}$ ratios exceeded the critical value $(p \leq 0.05)$, the Newman Keul's post hoc test was used to compare experimental means.

\section{RESULTS}

\section{IL-6, LIF, CNTF TRANSCRIPT EXPRESSION IN UROTHELIUM AND DETRUSOR SMOOTH MUSCLE WITH CYP-INDUCED CYSTITIS}

The regulation of IL-6, LIF, and CNTF transcripts was examined by Q-PCR analyses (Figures 1A-C) in urothelium and detrusor smooth muscle. IL-6 transcript expression significantly $(p \leq 0.01)$ 


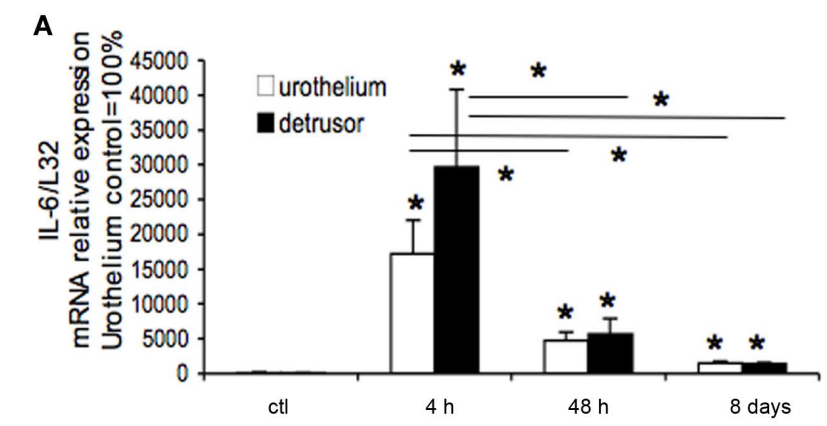

B
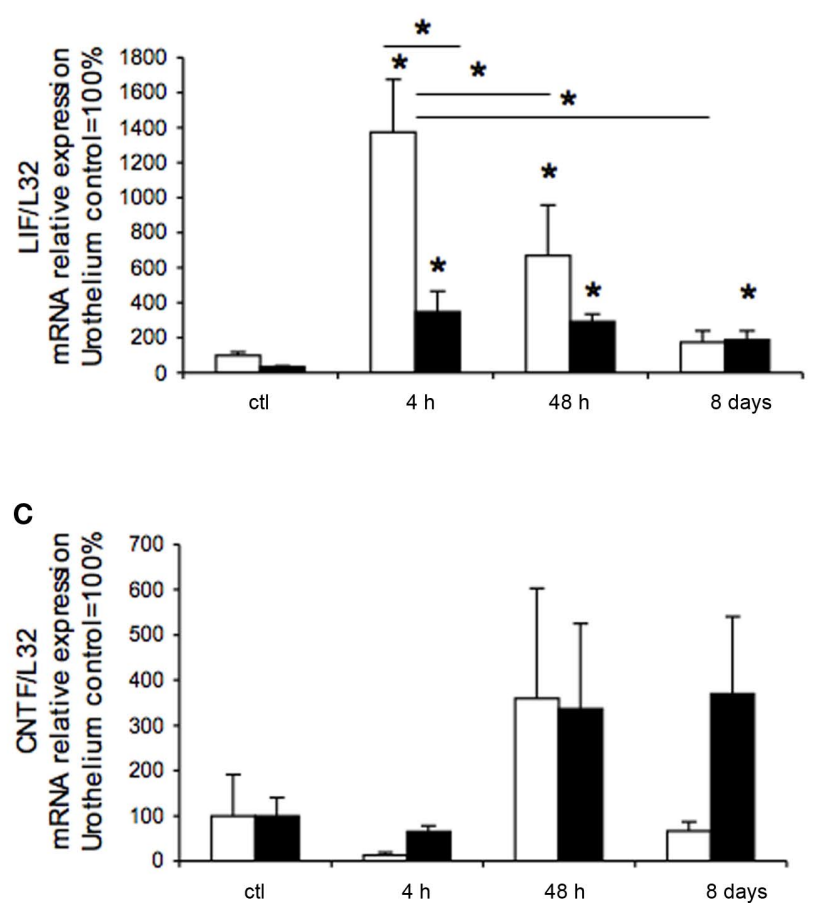

FIGURE 1 | Regulation of interleukin (IL)-6 type cytokines and receptors in urothelium and detrusor smooth muscle with cyclophosphamide (CYP)-induced cystitis. IL-6 (A), leukemia inhibitory factor [LIF; (B)], ciliary neurotrophic factor [CNTF; (C)], IL-6 receptor [R; (D)] $\alpha$, LIFR (E), and gp130 (F) transcript level in control and after $4 \mathrm{~h}, 48 \mathrm{~h}$, and chronic (8 days CYP-induced bladder inflammation. (A-F) Summary histograms of relative expression of the

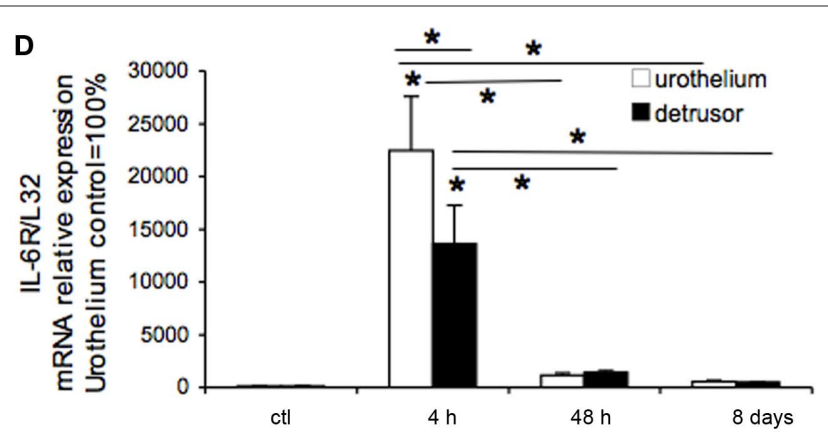

E
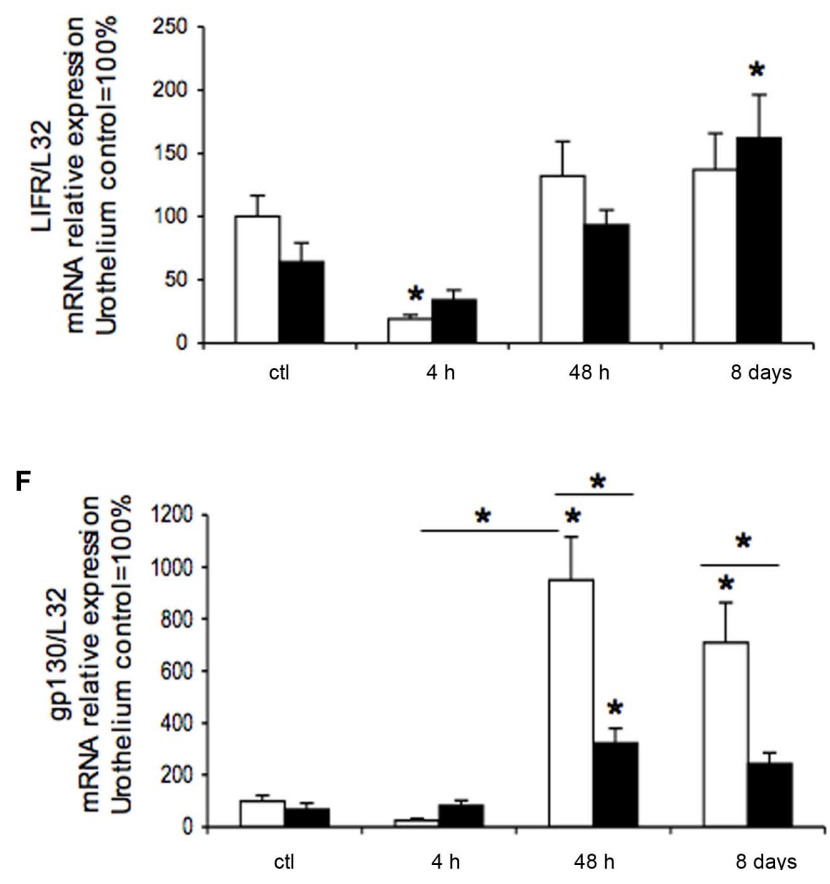

transcript expressed in urothelium and detrusor smooth muscle. Urothelium samples were set equal to $100 \%$ and normalized to the relative expression of the housekeeping gene, L32. Detrusor samples were expressed relative to urothelium samples and normalized to the relative expression of the housekeeping gene, L32. $n=6$ for each group; ${ }^{*} p \leq 0.01$ versus control or as indicated between groups by horizontal lines. increased in urothelium and detrusor smooth muscle with CYPinduced cystitis ( $4 \mathrm{~h}, 48 \mathrm{~h}$, and chronic) compared to control (Figure 1A). IL-6 mRNA expression in urothelium or detrusor smooth muscle after $4 \mathrm{~h}$ CYP treatment was significantly $(p \leq 0.01)$ greater than the 48 -h or chronic time point in the same tissues (Figure 1A). Q-PCR analyses demonstrated a significant ( $p \leq 0.01)$ increase in LIF mRNA in urothelium and detrusor smooth muscle with CYP-induced cystitis ( $4 \mathrm{~h}, 48 \mathrm{~h}$, and chronic) compared to control (Figure 1B). LIF mRNA expression in urothelium after $4 \mathrm{~h}$ CYP treatment was significantly $(p \leq 0.01)$ greater than the 48 -h or chronic time point (Figure 1B). LIF mRNA expression in detrusor muscle was significantly increased with each duration of CYP treatment (Figure 1B) and the magnitude of change was consistent across time points. LIF mRNA expression in urothelium was significantly $(p \leq 0.01)$ greater than that in detrusor smooth muscle with
$4 \mathrm{~h}$ CYP treatment (Figure 1B). In contrast, no changes in CNTF mRNA expression in urothelium or detrusor smooth muscle were observed with CYP-induced cystitis of any duration (Figure 1C). Due to the absences of changes in CNTF mRNA expression in urinary bladder with CYP-induced cystitis (Figure 1C), no additional characterization of CNTF or the non-signaling $\alpha$-receptor, CNTFR $\alpha$, was performed.

\section{IL-6R $\alpha$, LIFR, GP130 TRANSCRIPT EXPRESSION IN UROTHELIUM AND DETRUSOR SMOOTH MUSCLE WITH CYP-INDUCED CYSTITIS}

The regulation of IL-6R $\alpha$, LIFR, gp130 transcripts was examined by Q-PCR analyses (Figures 1D-F) in urothelium and detrusor smooth muscle. IL-6R $\alpha$ transcript expression significantly $(p \leq 0.01)$ increased in urothelium and detrusor smooth muscle with 4 h CYPinduced cystitis compared to control (Figure 1D). IL-6R $\alpha$ mRNA 
expression in urothelium or detrusor smooth muscle after $4 \mathrm{~h}$ CYP treatment was significantly $(p \leq 0.01)$ greater than the 48 -h or chronic time point in the same tissues (Figure 1D). With $4 \mathrm{~h}$ CYP-induced cystitis, IL-6R $\alpha$ transcript expression was significantly greater in urothelium compared to detrusor smooth muscle (Figure 1D). Q-PCR analyses demonstrated a significant $(p \leq 0.01)$ decrease in LIFR mRNA in urothelium and $4 \mathrm{~h}$ CYP-induced cystitis compared to control; no differences in urothelium LIFR mRNA were observed at $48 \mathrm{~h}$ or chronic time points (Figure 1E). LIFR mRNA expression in detrusor with chronic CYP treatment was significantly $(p \leq 0.01)$ increased compared to control (Figure 1E).gp130 mRNA expression was significantly $(p \leq 0.01)$ increased in urothelium and detrusor smooth muscle with 48 h CYP treatment (Figure 1F); gp130 mRNA expression was significantly $(p \leq 0.01)$ greater in urothelium compared to detrusor. gp130 mRNA expression was also significantly $(p \leq 0.01)$ increased in urothelium with chronic CYP treatment and expression was significantly $(p \leq 0.01)$ greater than that observed in detrusor smooth muscle (Figure 1F).

\section{IL-6, LIF, AND GP130 PROTEIN EXPRESSION AND EFFECTS OF CYCLOPHOSPHAMIDE-INDUCED CYSTITIS IN THE WHOLE RAT URINARY BLADDER}

Interleukin-6, LIF, and gp130 protein expression increased significantly ( $p \leq 0.01)$ following $4 \mathrm{~h}$ (3.3- to 5.3-fold), $48 \mathrm{~h} \mathrm{(2.9- \text {to }}$ 3.8-fold), and chronic (2.2- to 2.3-fold) CYP treatment as determined with Western blot analyses (Figures 2A-D). Four hours CYP treatment induced the greatest upregulation of IL-6 (5.3-fold), LIF (3.5-fold), and gp130 (3.3-fold) expression, which was significantly $(p \leq 0.01)$ greater than expression after chronic CYP treatment (Figures 2B-D) and significantly $(p \leq 0.01)$ greater than $48 \mathrm{~h} \mathrm{CYP}$ treatment in the case of IL-6 (Figure 2B).

\section{UROTHELIUM LIF-IR IN RATS AFTER INDUCTION OF CYSTITIS}

The expression of LIF-IR was very weak in the urothelium of urinary bladder whole mounts or cryostat bladder sections from control (Figures 3 and 4) rats. With acute CYP treatment (4 h), some diffuse LIF-IR was observed in the urothelium but more intense LIF-IR was observed in the lamina propria (Figure 3). Semi-quantitative analyses revealed significant increases in LIF-IR in the urothelium $4 \mathrm{~h}(p \leq 0.05)$ and $48 \mathrm{~h}(p \leq 0.01)$ after CYP treatment (Figure 3). Sustained LIF-IR was observed in the lamina propria (Figure 3) with CYP treatment. LIF-IR was significantly $(p \leq 0.01)$ increased in the urothelium with chronic CYP treatment (Figures 3 and 4). No regional differences in LIF-IR in the urothelium of the dome, body, or neck regions of the urinary bladder were observed in control or CYP-treated rats. LIF-IR was observed in all cell layers (apical, intermediate, and basal) of the urothelium.

\section{LIF-IR IN SUBUROTHELIAL PLEXUS WITH CYP-INDUCED CYSTITIS}

In whole mount preparations, LIF-IR was infrequently and faintly observed in the suburothelial nerve plexus throughout the entire control urinary bladder (Figure 4). CYP treatment (48 h and chronic) increased the appearance of LIF-IR in the suburothelial plexus (Figure 4). The density of the LIF-IR in suburothelial nerve fibers was greatest in the neck region with CYP treatment and our analysis of CYP-induced effects was restricted to this region. A significant $(p \leq 0.01)$ increase in the density of the LIF-IR nerve fibers in the bladder neck region was observed with $48 \mathrm{~h}$ (4.5fold increase) and chronic (10.1-fold increase) CYP treatment (Figure 4). Fine and thicker caliber LIF-IR neuronal fibers were observed (Figure 4) in the suburothelial plexus with CYP treatment. No changes in the LIF-IR suburothelial nerve plexus were

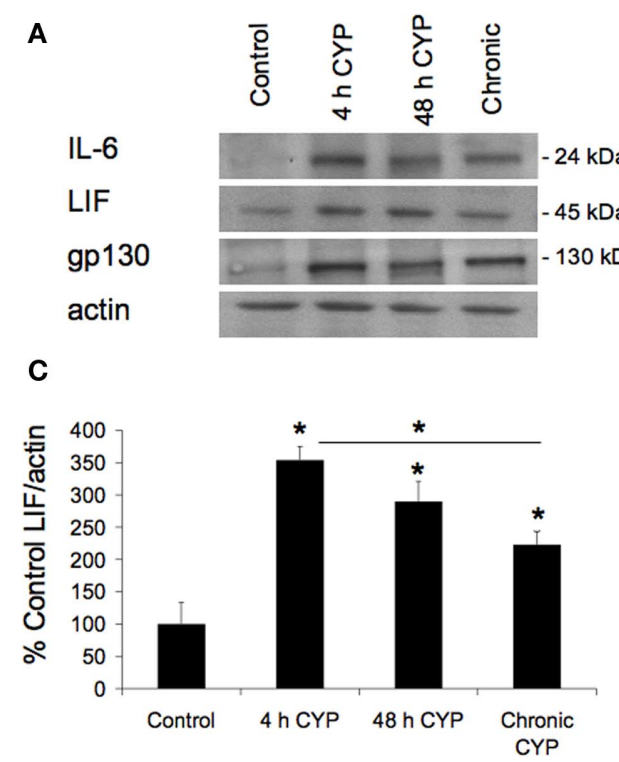

FIGURE 2 | Interleukin-6, LIF, and gp130 protein expression in whole bladder using Western blotting. (A) Representative Western blot examples of IL-6, LIF, and gp130 expression in whole urinary bladders $(25 \mu \mathrm{g})$ from control rats and those treated with cyclophosphamide (CYP) of varying duration. Actin expression was used as a loading control. (B-D) Summary histogram of relative
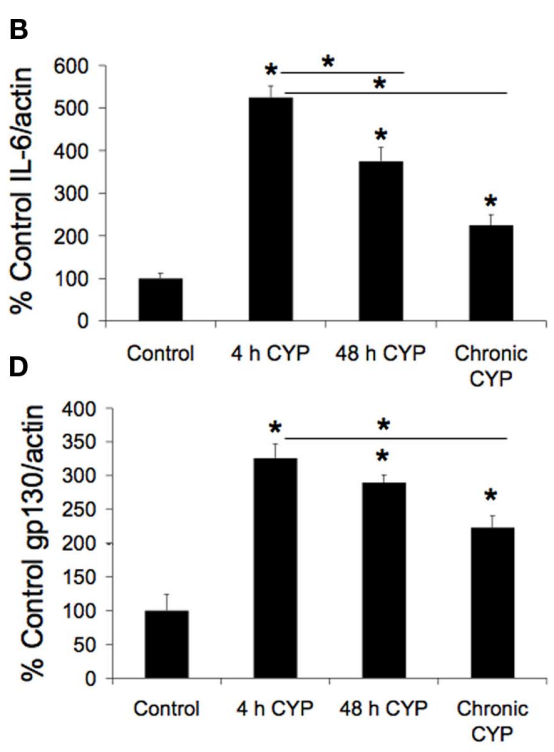

IL-6 (B), LIF (C), gp130 (D) band density in each group normalized to total actin expressed as a percentage of control (no inflammation). CYP-induced cystitis significantly $(p \leq 0.01$ ) increased IL-6, LIF, and gp130 expression in comparison to control urinary bladder. ${ }^{*} p \leq 0.01$ versus control or as indicated between groups by horizontal lines. $n=6$ for each group. 

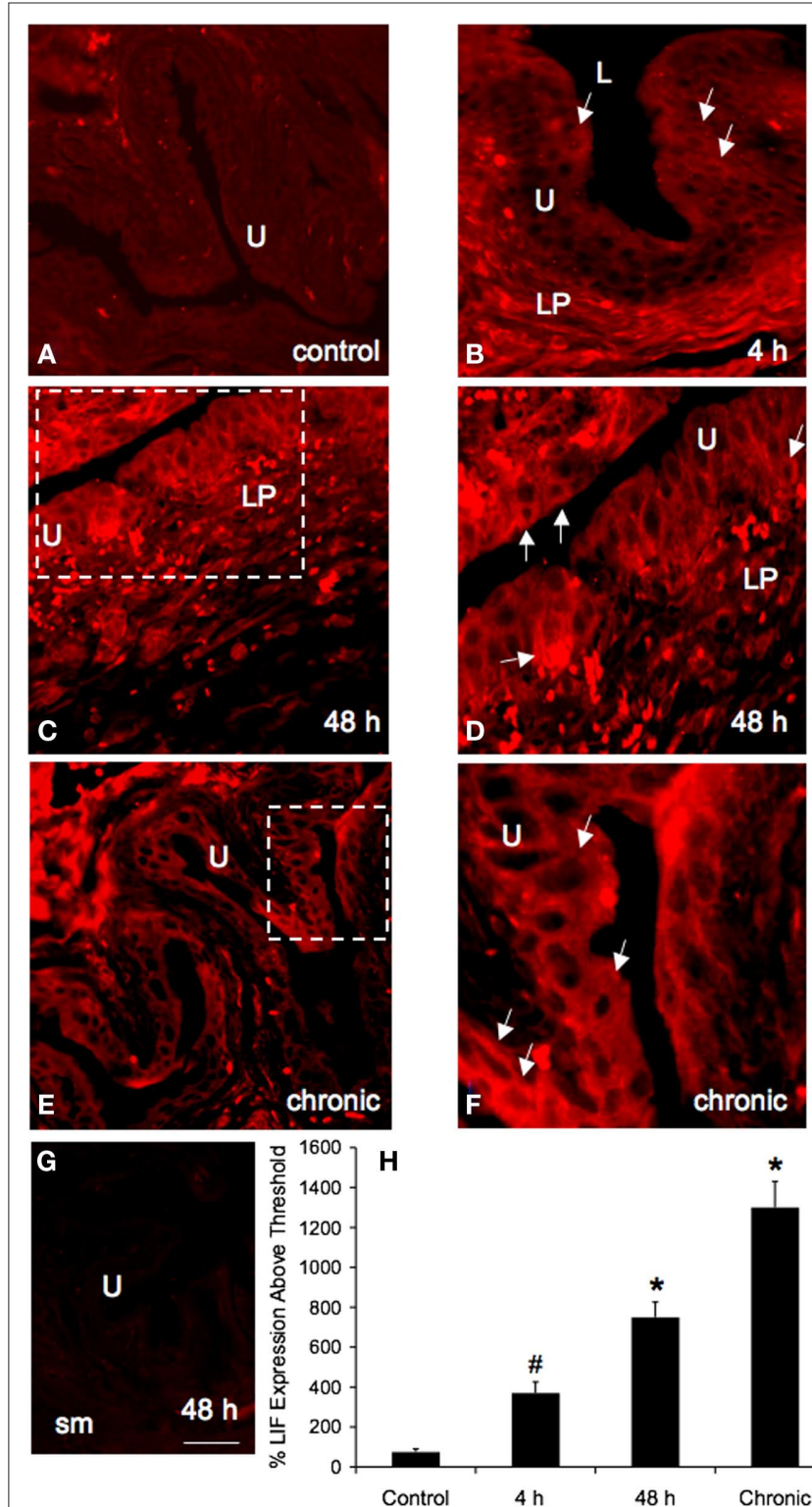

$\mathbf{H}$

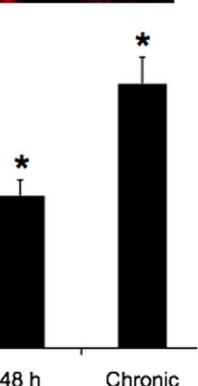

FIGURE 3 | Leukemia inhibitory factor-immunoreactivity (IR) in cryostat sections of urothelium $(U)$ after varying durations of CYP treatment. CYP treatment [4 h (B), $48 \mathrm{~h}(\mathbf{C}, \mathbf{D})$, chronic (E,F)] significantly ( $p \leq 0.05-0.01$ ) upregulated the percent of LIF-IR in $U$ in comparison control (A). Higher power fluorescence images of selected regions (white dashed boxes) in (C,E) are shown in (D,F). For all images, exposure times were held constant, and all tissues were processed simultaneously. In 4 h, 48 h, and chronic CYP-treated rats, LIF expression was visible in the $U$ (B-F) and lamina propria [LP; (B-D)], whereas control (A) urinary bladder showed little or no LIF-IR. Calibration bar represents $50 \mu \mathrm{m}$ in $(\mathbf{A}, \mathbf{C}, \mathbf{E}, \mathbf{G})$ and $25 \mu \mathrm{m}$ in (B,D,F,G): Immunoabsorptions with LIF peptide $(5 \mu \mathrm{g} / \mathrm{ml})$ and antisera in bladder sections resulted in no staining above background. (H) Histogram of the percent of LIF expression above threshold in the urothelium of CYP-treated rats ( $4 \mathrm{~h}, 48 \mathrm{~h}$, and chronic) expressed as a percentage of control. CYP treatment ( $4 \mathrm{~h}, 48 \mathrm{~h}$, and chronic) significantly (\#, $p \leq 0.05 ;{ }^{*}, p \leq 0.01$ ) upregulated LIF-IR in the urothelium. sm, smooth muscle. Data are a summary of $n=6$ for each group.

observed with $4 \mathrm{~h}$ CYP treatment (data not shown). LIF-IR in the suburothelial nerve plexus also exhibited IR for the pan neuronal marker, protein gene product 9.5 (PGP9.5; Figure 4).

\section{LIF-IR IN DETRUSOR SMOOTH MUSCLE WITH CYP-INDUCED CYSTITIS}

In urinary bladder sections from control rats, detrusor smooth muscle expression of LIF-IR was weak in all bladder regions examined (dome, body, neck; Figure 5). A significant ( $p \leq 0.01)$ increase in LIF-IR in detrusor smooth muscle was observed in all urinary bladder regions and at all time points examined ( $4 \mathrm{~h}, 6.7$-fold; 48 h, 6.5-fold; chronic, 6.2-fold; Figure 5). No differential regional expression of LIF-IR in the detrusor muscle was observed with any duration of CYP treatment.

\section{UROTHELIUM GP130-IMMUNOREACTIVITY IN RATS AFTER INDUCTION OF CYSTITIS}

The IL-6 family of cytokines including IL-6 and LIF, form receptor complexes through different combinations of signaling receptor subunits with gp130 being used by all family members. Thus, in these studies, gp130-IR was characterized in urothelium, suburothelial plexus and detrusor smooth muscle (see below) in control rats and in rats following CYP treatment of varying duration. The expression of gp130-IR was present in the urothelium of cryostat bladder sections from control rats being primarily present in apical urothelial cells (Figure 6). With acute (4, $48 \mathrm{~h}$ ) and chronic CYP treatment, gp130-IR was increased in the urothelium with gp130-IR being present in additional urothelial layers (i.e., intermediate; Figure 6). In urinary bladder from control and CYP-treated rats, no gp130-IR was present in the lamina propria (Figure 6). In addition, mo evidence of gp130-IR in the suburothelial nerve plexus was observed in cryostat bladder sections (Figure 6) or in whole mount bladder preparations (data not shown). Semiquantitative analyses revealed significant $(p \leq 0.01)$ increases in gp130-IR in the urothelium with CYP treatment ( 4 h, 48 h, chronic; Figure 6). No regional differences in gp130-IR in the urothelium of the dome, body, or neck regions of the urinary bladder were observed in control or CYP-treated rats.

\section{GP130-IMMUNOREACTIVITY IN DETRUSOR SMOOTH MUSCLE WITH CYP-INDUCED CYSTITIS}

In urinary bladder sections from control rats, detrusor smooth muscle expression of gp130-IR was weak in all bladder regions examined (dome, body, neck; Figure 7). CYP-induced cystitis significantly $(p \leq 0.01)$ increased gp130-IR in detrusor smooth muscle in all urinary bladder regions and at all time points examined $(4 \mathrm{~h}$, 5.7-fold; 48 h, 7.8-fold; chronic, 5.3-fold; Figure 7). No differential regional expression of gp130-IR in the detrusor muscle was observed with any duration of CYP treatment.

\section{DISCUSSION}

These studies demonstrated upregulation of IL- 6 and LIF transcript and protein expression in urinary bladder with CYP-induced cystitis of varying duration. In contrast, no changes in CNTF transcript expression were observed in urothelium or detrusor smooth muscle with CYP-induced cystitis. Previous studies showed that blockade of JAK2 reduced urinary bladder hyperreflexia and referred, somatic sensitivity in CYP-treated rats (Cheppudira et al., 2009). LIF and IL-6 may represent two potential upstream mediators of JAK/STAT signaling. LIF protein expression was localized to the urothelium, detrusor smooth muscle, and suburothelial nerve plexus in urinary bladder and expressed increased with CYP-induced cystitis. 

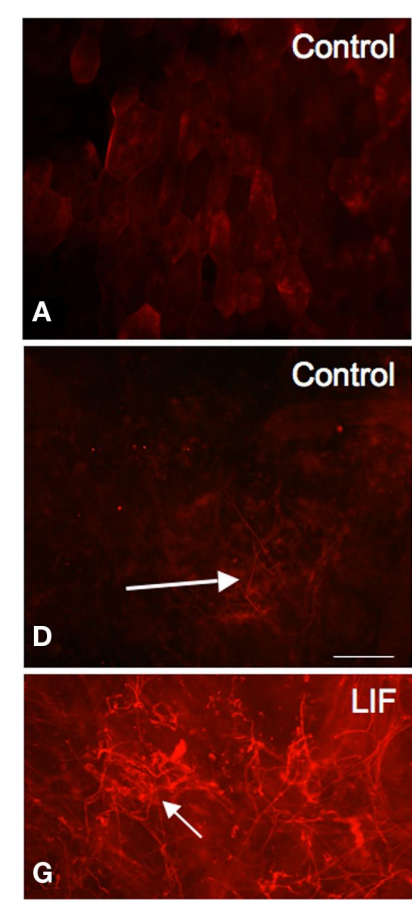

LIF

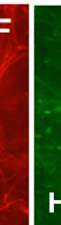

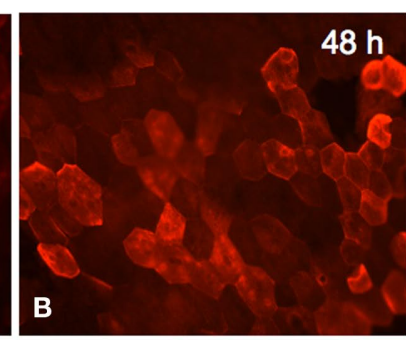
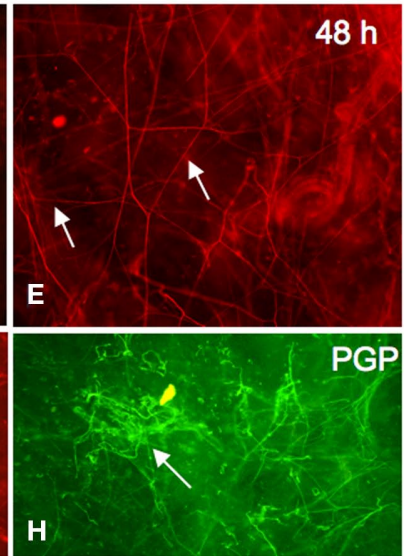
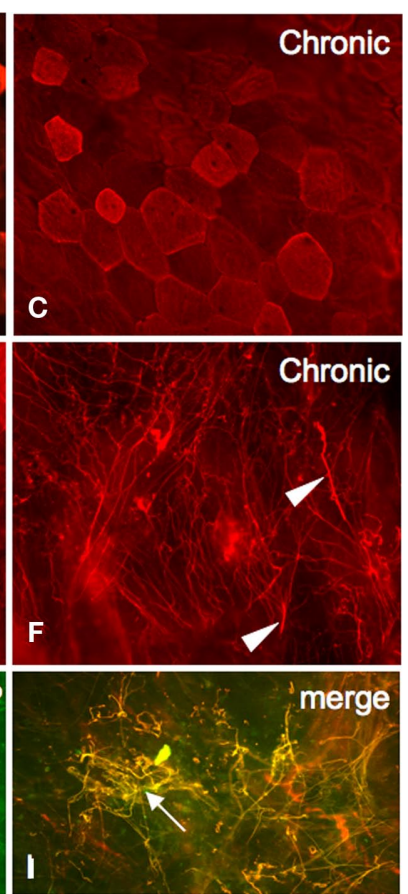

FIGURE 4 | Fluorescence photographs of LIF-immunoreactivity (IR) in urothelial cells and suburothelial plexus in the bladder neck region in whole mount preparations of the urinary bladder. In control (A) whole mount preparations, LIF-IR is weak compared to preparations from $48 \mathrm{~h}$ CYP-treated

(B), and chronic CYP-treated (C) rats. LIF-IR in the suburothelial nerve plexus in the neck region increased in density with CYP-induced cystitis [48 h (E) and chronic (F)] compared to control (D). Arrows (D,E) and arrowheads (F) indicate small or large caliber LIF-IR nerve fibers respectively. With CYP treatment [chronic, (G-I)], LIF-IR in nerve fibers (G) in the suburothelial plexus exhibited complete overlap (I) with PGP9.5 (H), a pan neuronal marker. Calibration bar represents $80 \mu \mathrm{m}$.
Changes in IL-6Ro, LIFR, and gp130 transcript expression were also identified in urinary bladder and changes in transcript expression were dependent upon duration of CYP-induced cystitis. gp130 protein expression was also identified in the urothelium and detrusor smooth muscle but absent in the suburothelial nerve plexus. These studies extend the list of cytokines and associated receptors whose expression in urinary bladder is changed with urinary bladder inflammation.

Pain associated with BPS/IC may involve an alteration of visceral sensation/bladder sensory physiology. Altered visceral sensations from the urinary bladder (i.e., pain at low or moderate bladder filling) that accompany BPS/IC (Petrone et al., 1995; Ho et al., 1997; Johansson et al., 1997; Driscoll and Teichman, 2001; Sant and Hanno, 2001) may be mediated by many factors including changes in the properties of peripheral bladder afferent pathways such that bladder afferent neurons respond in an exaggerated manner to normally innocuous stimuli (allodynia). The present studies suggest that LIF and IL-6, members of the IL- 6 family of cytokines, produced in the urinary bladder after CYP-induced cystitis may also contribute to this sensitization process and influence referred somatic sensitization and/or urinary bladder hyperreflexia in CYP-treated rats. The present study has demonstrated that a variety of urinary bladder components (urothelial cells, detrusor smooth muscle and bladder nerve fibers) express IL-6 and LIF and that transcript and protein expression is increased with CYP-induced cystitis of varying duration.
Urothelial dysfunction has been proposed as an underlying cause or contributing factor in BPS/IC (Birder and de Groat, 2007). The cause(s) of this dysfunction is not known; however, several studies have shown that activation of bladder mast cells followed by release of cytokines contributes to urothelial dysfunction resulting in abnormal bladder activity and pain (Sant et al., 2007). IL-6 expression is markedly increased in urine (Erickson et al., 2002; Sairanen et al., 2008) and urothelium (Peeker et al., 2000) of individuals with IC/BPS. Current studies suggest additional sources of cytokines and associated receptors to include the urothelium, detrusor smooth muscle, and suburothelial nerve plexus. Our immunohistochemical and Q-PCR data demonstrate that LIF and IL-6 protein and transcript expression are significantly increased in the urothelium and detrusor smooth muscle and LIF is additionally expressed in the suburothelial nerve plexus with CYP-induced cystitis. LIF and IL-6 transcript and protein expression were increased with acute ( $4 \mathrm{~h}, 48 \mathrm{~h}$ ) and chronic (8 day) bladder inflammation. Changes in LIF mRNA and protein expression were largely complementary with CYP-induced cystitis. In contrast, CNTF mRNA expression was not changed in urothelium or detrusor smooth muscle with CYP-induced cystitis. This suggests that LIF and IL-6 contribute to both acute and chronic aspects of bladder inflammation and expression of these cytokines is found in multiple tissue sources in the urinary bladder.

A previous study from our laboratory demonstrated increased cytokine expression [e.g., interferon (IFN)-gamma, IL, and TNF$\alpha / \beta$ after CYP-induced cystitis; Malley and Vizzard, 2002].A recent 

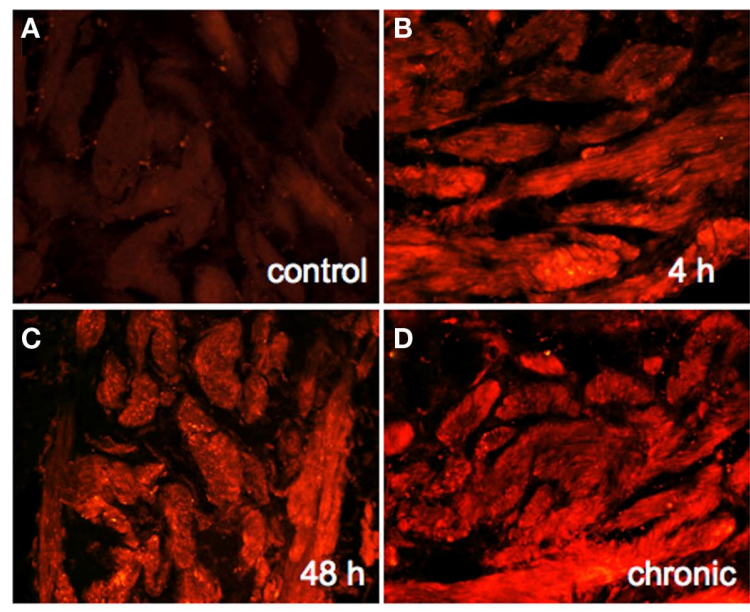

E

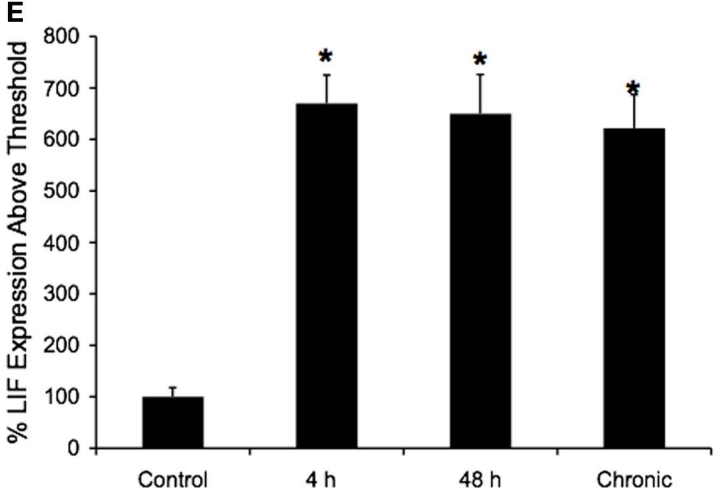

FIGURE 5 | Fluorescence photographs of LIF-immunoreactivity (IR) in detrusor smooth muscle in the bladder neck region in whole mount preparations of the urinary bladder in control (A), $4 \mathrm{~h}$ CYP-treated (B), $48 \mathrm{~h}$ CYP-treated (C), and chronic CYP-treated (D) rats. LIF-IR in the detrusor smooth muscle increased in density with CYP-induced cystitis (4 h, $48 \mathrm{~h}$, chronic). (E) Summary histogram of percent LIF expression above threshold in detrusor smooth muscle with CYP-induced cystitis. Data are a summary of $n=6$ for each group. ${ }^{*} p \leq 0.01$ versus control. Calibration bar represents $80 \mu \mathrm{m}$.

study has also demonstrated upregulation of IL-6 transcript and protein expression in the submucosal layer of bladder after CYP treatment in mice (Nishii et al., 2006). The current demonstration of CYP-induced upregulation of IL- 6 and LIF expression in the urinary bladder adds to the growing list of cytokines or chemokines that may play role(s) BPS/IC (Lamale et al., 2006) although some controversy exists relating to the usefulness of cytokines (i.e., IL-6) as a biomarker for BPS/IC (Daha et al., 2007). Our examination of LIF and IL-6 expression with bladder inflammation is consistent with previous demonstrations of LIF and IL-6 upregulation after peripheral nerve injury, inflammation (Banner and Patterson, 1994; Curtis et al., 1994; Patterson, 1994; Banner et al., 1998) or systemic inflammation (Brown et al., 1994).

Studies involving LIF knockout (KO) mice and pharmacological studies involving LIF and IL- 6 administration to sensory neurons have demonstrated that both regulate neurochemical plasticity in dorsal root ganglion (DRG) and sympathetic neurons after peripheral nerve injury (Rao et al., 1993; Corness et al., 1996; Sun and Zigmond, 1996a; Zigmond et al., 1996; Thompson et al.,
1998). Our previous studies have demonstrated neurochemical plasticity in bladder afferent cells with CYP-induced cystitis that includes changes in neuropeptide expression (Vizzard, 2000c, 2001; Zvarova and Vizzard, 2006) and bladder function improvement with neuropeptide receptor blockade (Braas et al., 2006). It is possible that increased LIF and/or IL-6 expression in urinary bladder results in bladder hyperreflexia indirectly through subsequent upregulation of neuropeptides. Studies involving LIF- and IL-6 KO mice are necessary to address direct or indirect roles of LIF and IL- 6 in bladder hyperreflexia and somatic sensitivity following cystitis.

The present study adds cytokines to the list of potential mediators that may contribute to altered micturition reflexes after cystitis. A significant body of literature exists to support the concept that cytokines are key signals that are released in the periphery, including the urinary bladder (Saban, 2001; Saban et al., 2001a,b), to signal the central nervous system that infection/inflammation has occurred (Lindholm et al., 1987; Dinarello, 1998; Poole and Woolf, 1998; Poole et al., 1998; Maier and Watkins, 1999). LIF and IL-6 transcript and protein expression in the urothelium and detrusor and the maintenance of the responses through acute, intermediate, and chronic CYP-induced cystitis suggest that IL-6 family members in particular, may contribute to neuroplasticity in lower urinary tract reflexes after cystitis. LIF modulates the initial neuroinflammatory response to neural injury and also regulates neuronal responses to injury through direct effects on immune cells (Gadient and Otten, 1997) or through activation of neuropeptides (Rao et al., 1993; Corness et al., 1996; Sun and Zigmond, 1996a; Zigmond et al., 1996). Although evidence suggests that LIF acts as a pro-inflammatory mediator (Patterson, 1994; Sun and Zigmond, 1996b; Sugiura et al., 2000), other evidence indicates LIF functions as an antiinflammatory and analgesic cytokine (Ulich et al., 1994; Banner et al., 1998). IL-6, on the other hand, is generally considered to be pro-inflammatory (Gadient and Otten, 1997; Parkin and Cohen, 2001) and has numerous biological activities including: promotion of neuronal survival, protection against neuronal damage, induction of neuronal differentiation, modulation of neurotransmitter/ neuromodulator synthesis, and modulation of pain (Gadient and Otten, 1997; Parkin and Cohen, 2001).

Individuals with BPS/IC report a predominance of suprapubic pain as well as urethral, genital, and non-genitourinary pain. In addition, hypersensitivity to somatic stimuli has been observed in subjects with BPS/IC (Fitzgerald et al., 2005; Ness, 2005). A number of reports have demonstrated referred somatic hypersensitivity in animal models of urinary bladder inflammation including CYP (Guerios et al., 2008; Studeny et al., 2008). In previous studies (Cheppudira et al., 2009), we demonstrated a reduction in hind paw sensitivity in rats treated with CYP $(4 \mathrm{~h})$ and a reduction in CYP-induced urinary bladder hyperreflexia when rats were also treated with a JAK2 inhibitor, AG490. In addition, blockade of the STAT3 pathway with AG490 attenuated mechanical allodynia and thermal hyperalgesia after peripheral nerve injury (Dominguez et al., 2008). Intrathecal IL-6 injection produces allodynia and hyperalgesia after peripheral nerve injury and intrathecal IL-6 neutralizing antibody decreases allodynia (Arruda et al., 2000). The present studies have identified LIF and IL- 6 as two potential upstream activators of JAK/STAT signaling in CYP-induced cystitis. 

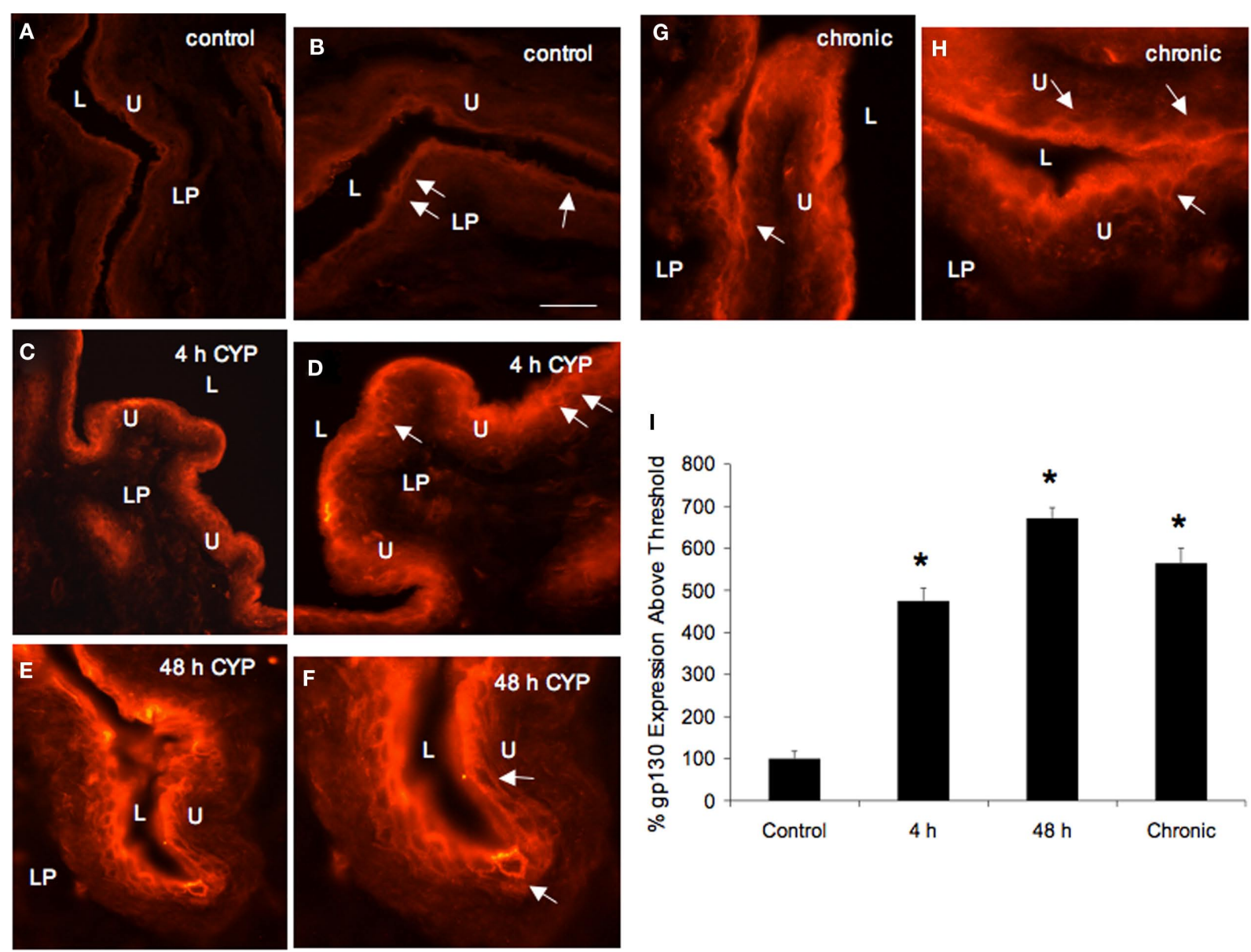

FIGURE 6 | gp130-immunoreactivity (IR) in urothelium (U) and increased expression with CYP-induced cystitis. $(\mathbf{A}, \mathbf{B})$ gp 130-IR in control $U$ is weakly expressed and is restricted to apical urothelial cells (arrows). With $4 \mathrm{~h}$ (C,D), $48 \mathrm{~h}$ $(\mathbf{E}, \mathbf{F})$, and chronic $(\mathbf{G}, \mathbf{H})$ CYP-induced cystitis, gp130-IR is increased in intensity and additional urothelial layers (i.e., intermediate) express gp130-IR. gp130-IR is

Follow-up studies involving IL-6 or LIF KO mice can be used to assess somatic sensitivity and bladder function in the presence and absence of urinary bladder inflammation.

Interleukin-6 and LIF form receptor complexes through different combinations of signaling receptor subunits with the receptor subunit, gp130, being shared by all family members (Gadient and Patterson, 1999). CYP-induced cystitis increased gp130 expression in the urothelium and detrusor smooth muscle of the urinary bladder but expression was not observed in the suburothelial nerve plexus, largely composed of afferent nerve fibers (Andersson and Wein, 2004). Although gp130-IR was not found in the suburothelial nerve plexus, cytokine signaling via gp 130 may contribute to functional bladder sensory physiology via urothelium-mediated mechanisms. The urothelium, once thought to provide an impermeable barrier only, is now suggested to have "neuron-like" properties such as plasticity and sensory, transduction, and signaling capabilities, especially in the context of bladder inflammation (Birder, 2006; Apodaca et al., 2007; Birder and de Groat, 2007; Birder et al., 2009). Urothelial cells share a number of similarities with sensory neurons, including some consistency in the expression of receptors and

absent from the lamina propria (LP) of the urinary bladder from control or CYP-treated rats. (I) Summary histogram of percent gp130 expression above threshold in $U$ with CYP-induced cystitis. Data are a summary of $n=6$ for each group. ${ }^{*} p \leq 0.01$ versus control. L, lumen. Calibration bar represents $80 \mu \mathrm{m}$ in (A,C,E,G) and $45 \mu \mathrm{m}$ in $(\mathbf{B}, \mathbf{D}, \mathbf{F}, \mathbf{H})$

channels (Birder, 2006; Apodaca et al., 2007; Birder and de Groat, 2007; Birder et al., 2009). The present demonstration of gp130 protein and transcript expression as well as IL-6R $\alpha$ and LIFR transcript expression in the urothelium extends the list of similarities between sensory neurons and urothelial cells as gp 130, IL-6R $\alpha$, and LIFR are expressed in DRG cells (Gardiner et al., 2002). Although both Q-PCR and protein analyses of gp130 revealed increases in transcript and protein expression with CYP-induced cystitis, the time course of the increase differed. This difference may reflect earlier changes in post-translational processing compared to de novo transcription. Urothelial-mediated communication with the detrusor smooth muscle, suburothelial plexus, and/or interstitial cells has been suggested because of functional receptor expression and secretion capabilities of the urothelium (Birder, 2006; Apodaca et al., 2007; Birder and de Groat, 2007; Birder et al., 2009). IL-6 and LIF interactions with receptors (IL-6R $\alpha$, gp 130, and LIFR) may facilitate the release of urothelial-derived mediators such as ATP, $\mathrm{NO}$, or chemokines that may then influence the suburothelial nerve plexus to affect micturition function via urothelium-to-neuron communication (Birder, 2006; Apodaca et al., 2007; Birder and de 

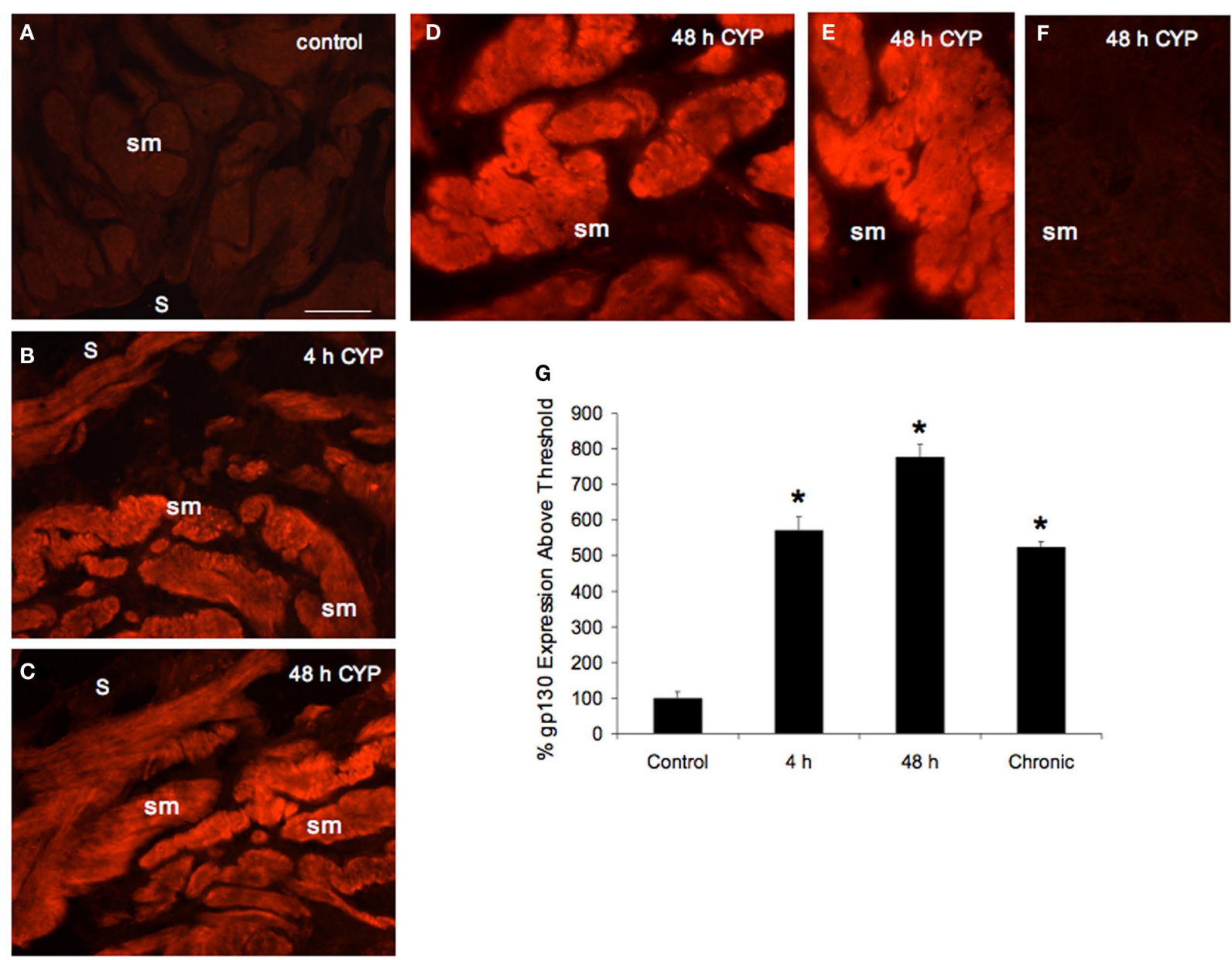

FIGURE 7 | gp130-Immunoreactivity (IR) in detrusor smooth muscle (sm) and increased expression with CYP-induced cystitis. (A) gp130-IR in control sm is very weakly expressed. With $4 \mathrm{~h}$ (B), $48 \mathrm{~h}$ (C-E) and chronic CYP-induced cystitis, gp130-IR is increased in intensity throughout the sm. (F) Immunoabsorptions with gp130 peptide $(5 \mu \mathrm{g} / \mathrm{ml})$ and antisera in bladder sections resulted in no staining above background. (G) Summary histogram of percent gp130 expression above threshold in sm with CYP-induced cystitis. Data are a summary of $n=6$ for each group. ${ }^{*} p \leq 0.01$ versus control. S, serosa. Calibration bar represents $80 \mu \mathrm{m}$ in (A-C,F), $45 \mu \mathrm{m}$ in (D), and $25 \mu \mathrm{m}$ in (E).
Groat, 2007; Birder et al., 2009). Future studies determining IL-6or LIF-induced release of ATP or NO using cultured rat urothelial cells can address this possibility. Given the increased expression of gp130, LIFR (chronic cystitis), and IL-6R $\alpha$ in detrusor smooth muscle, cytokine/receptor signaling may also originate from the detrusor smooth muscle.

In summary, these studies have demonstrated significant alterations in urinary bladder IL-6, LIF mRNA, and protein expression in urinary bladder following CYP-induced cystitis examined at three time points (acute, intermediate, and chronic). LIF protein expression was localized to the urothelium, detrusor, and suburothelial plexus. Increased transcript expression IL-6 type cytokine receptors including IL-6R $\alpha$, LIFR (chronic cystitis), and gp130 was also demonstrated in urinary bladder after CYP-induced cystitis. gp130 protein expression was localized to the urothelium and detrusor. Cytokines produced in the urinary bladder may, alone or in combination with other cytokines (Gadient et al., 1990; Woolf et al., 1997), chemokines (Arms et al., 2010), or neurotrophic factors (Poole and Woolf, 1998) also upregulated in the urinary bladder (Vizzard, 2000b), contribute to neurochemical (Vizzard, 1997, 2000c, 2001), electrophysiological (Jennings and Vizzard, 1999; Yoshimura and de Groat, 1999) and organizational (Vizzard, 2000a) changes demonstrated in the lower urinary tract following CYP-induced cystitis. Future studies are necessary to determine the functional contribution of LIF and IL-6 to neural plasticity after cystitis and subsequent activation of JAK/STAT signaling in urinary bladder using pharmacological approaches and/or LIF and IL-6 KO mice.

\section{ACKNOWLEDGMENTS}

The authors gratefully acknowledge the technical expertise and support provided by the VT Cancer Center DNA Analysis Facility. Dr. Cheppudira's current address is the Department of Pharmacology, University of Illinois at Chicago, Chicago, IL 60612, USA. This work was funded by NIH grants DK051369, DK060481, and DK065989. NIH Grant Number P20 RR16435 from the COBRE Program of the National Center also supported the project for Research Resources. 


\section{REFERENCES}

Abramoff, M. D., Magelhaes, P. J., and Ram, S. J. (2004). Image processing with ImageJ. Biophotonics Int. 11, 36-42.

Alexander, H. R., Billingsley, K. G., Block, M. I., and Fraker, D. L. (1994). D-factor/leukaemia inhibitory factor: evidence for its role as a mediator in acute and chronic inflammatory disease. Cytokine 6, 589-596.

Andersson, K. E., and Wein, A. J. (2004). Pharmacology of the lower urinary tract: basis for current and future treatments of urinary incontinence. Pharmacol. Rev. 56, 581-631.

Apodaca, G., Balestreire, E., and Birder, L. A. (2007). The uroepithelial-associated sensory web. Kidney Int. 72, 1057-1064.

Arms, L., Girard, B. M., and Vizzard, M. A. (2010). Expression and function of CXCL12/CXCR4 in rat urinary bladder with cyclophosphamide-induced cystitis. Am. J. Physiol. Renal Physiol. 298, F589-F600.

Arruda, J. L., Sweitzer, S. A., Rutkowski, M. D., and DeLeo, J.A. (2000). Intrathecal anti-IL-6 antibody and IgG attenuates peripheral nerve injury-induced mechanical allodynia in the rat: possible immune modulation in neuropathic pain. Brain Res. 879, 216-225.

Baba, H., Doubell, T. P., and Woolf, C. J. (1999). Peripheral inflammation facilitates a beta fiber-mediated synaptic input to the substantia gelatinosa of the adult rat spinal cord. J. Neurosci. 19, 859-867.

Banner, L. R., and Patterson, P. H. (1994). Major changes in the expression of the mRNAs for cholinergic differentiation factor/leukemia inhibitory factor and its receptor after injury to adult peripheral nerves and ganglia. Proc. Natl. Acad. Sci. U.S.A. 91, 7109-7113.

Banner, L. R., Patterson, P. H., Allchorne, A., Poole, S., and Woolf, C. J. (1998). Leukemia inhibitory factor is an antiinflammatory and analgesic cytokine. J. Neurosci. 18, 5456-5462.

Birder, L. A. (2006). Urinary bladder urothelium: molecular sensors of chemical/thermal/mechanical stimuli. Vascul. Pharmacol. 45, 221-226.

Birder, L. A., and de Groat, W. C. (2007). Mechanisms of disease: involvement of the urothelium in bladder dysfunction. Nat. Clin. Pract. Urol. 4, 46-54.

Birder, L. A., Hanna-Mitchell, A. T., and Kanai, A. (2009). "Neural-epithelial communication and visceral pain," in Visceral Pain, ed. D.E. Bjorling (Kerala: Research Signpost), 45-70.

Bouchelouche, K., Alvarez, S., Horn, T., Nordling, J., and Bouchelouche, P. (2006). Human detrusor smooth muscle cells release interleukin-6, inter- leukin-8, and RANTES in response to proinflammatory cytokines interleukin-1beta and tumor necrosis factor-alpha. Urology 67, 214-219.

Braas, K. M., May, V., Zvara, P., Nausch, B., Kliment, J., Dunleavy, J. D., Nelson, M. T., and Vizzard, M. A. (2006). Role for pituitary adenylate cyclase activating polypeptide in cystitis-induced plasticity of micturition reflexes. Am. J. Physiol. Regul. Integr. Comp. Physiol. 290, R951-R962.

Brady, C. M., Apostolidis, A. N., Harper, M., Yiangou, Y., Beckett, A., Jacques, T. S., Freeman, A., Scaravilli, F., Fowler, C. J., and Anand, P. (2004). Parallel changes in bladder suburothelial vanilloid receptor TRPV1 and panneuronal marker PGP9.5 immunoreactivity in patients with neurogenic detrusor overactivity after intravesical resiniferatoxin treatment. B.J.U. Int. 93, 770-776.

Brown, M. A., Metcalf, D., and Gough, N. M. (1994). Leukaemia inhibitory factor and interleukin 6 are expressed at very low levels in the normal adult mouse and are induced by inflammation. Cytokine 6, 300-309.

Cheppudira, B. P., Girard, B. M., Malley, S. E., Dattilio, A., Schutz, K. C., May, V., and Vizzard, M. A. (2009). Involvement of JAK-STAT signaling/ function after cyclophosphamide-induced bladder inflammation in female rats. Am. J. Physiol. Renal Physiol. 297, F1038-F1044.

Cheppudira, B. P., Girard, B. M., Malley, S. E., Schutz, K. C., May, V., and Vizzard, M. A. (2008). Upregulation of vascular endothelial growth factor isoform VEGF-164 and receptors (VEGFR-2, Npn-1, and Npn-2) in rats with cyclophosphamide-induced cystitis. Am. J. Physiol. Renal Physiol. 295, F826-F836.

Corness, J., Shi, T. J., Xu, Z. Q., Brulet, P., and Hokfelt, T. (1996). Influence of leukemia inhibitory factor on galanin/GMAP and neuropeptide $\mathrm{Y}$ expression in mouse primary sensory neurons after axotomy. Exp. Brain Res. 112, 79-88.

Corrow, K., Girard, B. M., and Vizzard, M. A. (2010). Expression and response of acid-sensing ion channels (ASICs) in urinary bladder to cyclophosphamide (CYP)-induced cystitis. Am. J. Physiol. Renal Physiol. 298, F1130-F1139.

Corrow, K. A., and Vizzard, M. A. (2007). Phosphorylation of extracellular signal-regulated kinases in urinary bladder in rats with cyclophosphamide-induced cystitis. Am. J. Physiol. Regul. Integr. Comp. Physiol. 293, R125-R134.

Curtis, R., Scherer, S. S., Somogyi, R., Adryan, K. M., Ip, N. Y., Zhu, Y., Lindsay, R. M., and DiStefano, P. S.
(1994). Retrograde axonal transport of LIF is increased by peripheral nerve injury: correlation with increased LIF expression in distal nerve. Neuron 12, 191-204.

Daha, L. K., Lazar, D., Simak, R., and Pfluger, H. (2007). Is there a relation between urinary interleukin-6 levels and symptoms before and after intravesical glycosaminoglycan substitution therapy in patients with bladder pain syndrome/interstitial cystitis? Int Urogynecol. J. Pelvic Floor Dysfunct. 18, 1449-1452.

Dinarello, C. A. (1998). "Overview of inflammatory cytokines and their role in pain," in Cytokines and Pain, eds L. R. Watkins and S. F. Maier (Boston: Birkhauser Verlag), 1-20.

Dinarello,C.A.D.(1997).Proinflammatory and anti-inflammatory cytokines as mediators in the pathogenesis of septic shock. Chest 112, 321S-329S.

Dominguez, E., Rivat, C., Pommier, B. Mauborgne, A., and Pohl, M. (2008). JAK/STAT3 pathway is activated in spinal cord microglia after peripheral nerve injury and contributes to neuropathic pain development in rat. $J$. Neurochem. 107, 50-60.

Dray, A. (1995). Inflammatory mediators of pain. Br. J. Anaesth. 75, 125-131.

Driscoll,A., and Teichman, J.M.H. (2001) How do patients with interstitial cystitis present? J. Urol. 166, 2118-2120.

Dziennis, S., and Alkayed, N. J. (2008) Role of signal transducer and activator of transcription 3 in neuronal survival and regeneration. Rev. Neurosci. 19, 341-361.

Erickson, D. R., Xie, S. X., Bhavanandan, V. P., Wheeler, M. A., Hurst, R. E., Demers, L. M., Kushner, L., and Keay, S.K. (2002).A comparison of multiple urine markers for interstitial cystitis. $J$. Urol. 167, 2461-2469.

Fitzgerald, M. P., Koch, D., and Senka, J. (2005). Visceral and cutaneous sensory testing in patients with painful bladder syndrome. Neurourol. Urodyn 24, 627-632.

Gadient, R. A., Cron, K. C., and Otten, U. (1990). Interleukin-1 beta and tumor necrosis factor-alpha synergistically stimulate nerve growth factor (NGF) release from cultured rat astrocytes. Neurosci. Lett. 117, 335-340.

Gadient, R. A., and Otten, U. H. (1997) Interleukin-6 (IL-6) - a molecule with both beneficial and destructive potentials. Prog. Neurobiol. 52, 379-390.

Gadient, R.A., and Patterson, P.H. (1999) Leukemia inhibitory factor, interleukin 6, and other cytokines using the GP130 transducing receptor: roles in inflammation and injury. Stem Cells 17, 127-137.

Gardiner, N. J., Cafferty, W. B., Slack, S. E., and Thompson, S. W. (2002).
Expression of gp130 and leukaemia inhibitory factor receptor subunits in adult rat sensory neurones: regulation by nerve injury. J. Neurochem. 83, 100-109.

Girard, B. M., May, V., Bora, S. H., Fina, F., and Braas, K. M. (2002). Regulation of neurotrophic peptide expression in sympathetic neurons: quantitative analysis using radioimmunoassay and real-time quantitative polymerase chain reaction. Regul. Pept. 109, 89-101.

Guerios, S. D., Wang, Z. Y., Boldon, K., Bushman, W., and Bjorling, D. E. (2008). Blockade of NGF and trk receptors inhibits increased peripheral mechanical sensitivity accompanying cystitis in rats. Am. J. Physiol. Regul. Integr. Comp. Physiol. 295, R111-R122.

Hanno, P., Lin, A., Nordling, J., Nyberg, L., van Ophoven, A., Ueda, T., and Wein, A. (2010). Bladder pain syndrome committee of the international consultation on incontinence. Neurourol. Urodyn. 29, 191-198.

Hibi, M., Murakami, M., Saito, M., Hirano, T., Taga, T., and Kishimoto, T. (1990). Molecular cloning and expression of an IL-6 signal transducer, gp130. Cell 63, 1149-1157.

Ho, N., Koziol, J. A., and Parsons, C. L. (1997). "Epidemiology of interstitial cystitis," in Interstitial Cystitis, ed. G. R. Sant (Philadelphia: Lippincott-Raven Publishers), 9-16.

Hu, V.Y., Malley, S., Dattilio, A., Folsom, J. B.,Zvara, P., and Vizzard, M.A. (2003). COX-2 and prostanoid expression in micturition pathways after cyclophosphamide-induced cystitis in the rat. Am. J. Physiol. Regul. Integr. Comp. Physiol. 284, R574-R585.

Hu, V.Y., Zvara, P., Dattilio, A., Redman, T. L., Allen, S. J., Dawbarn, D., Stroemer, R. P., and Vizzard, M. A. (2005). Decrease in bladder overactivity with REN1820 in rats with cyclophosphamide induced cystitis. J. Urol. 173 , 1016-1021.

Jennings, L. J., and Vizzard, M. A. (1999). Cyclophosphamide-induced inflammation of the urinary bladder alters electrical properties of small diameter afferent neurons from dorsal root ganglia. FASEB J. 13, A57.

Johansson, S. L., Ogawa, K., and Fall, M. (1997). "The pathology of interstitial cystitis," in Interstitial Cystitis, ed. G. R. Sant (Philadelphia: Lippincott-Raven Publishers), 143-152.

Kim, E. J., Simpson, P. J., Park, D. J., Liu, B. Q., Ronnett, G. V., and Moon, C. (2005). Leukemia inhibitory factor is a proliferative factor for olfactory sensory neurons. Neuroreport 16, 25-28.

Klinger, M. B., Dattilio, A., and Vizzard, M. A. (2007). Expression of 
cyclooxygenase- 2 in urinary bladder in rats with cyclophosphamide-induced cystitis. Am. J. Physiol. Regul. Integr. Comp. Physiol. 293, R677-R685.

Klinger, M. B., Girard, B., and Vizzard, M. A. (2008).p75(NTR) expression in rat urinary bladder sensory neurons and spinal cord with cyclophosphamideinduced cystitis. J. Comp. Neurol. 507, 1379-1392.

Klinger, M. B., and Vizzard, M. A. (2008). Role of p75NTR in female rat urinary bladder with cyclophosphamide-induced cystitis. Am. J. Physiol. Renal Physiol. 295, F1778-F1789.

Knight, D. (2001). Leukaemia inhibitory factor (LIF): a cytokine of emerging importance in chronic airway inflammation. Pulm. Pharmacol. Ther. 14, 169-176.

Lamale, L. M., Lutgendorf, S. K., Zimmerman, M. B., and Kreder, K. J. (2006). Interleukin-6, histamine, and methylhistamine as diagnostic markers for interstitial cystitis. Urology 68, 702-706.

Lindholm, D., Heumann, R., Meyer, M., and Thoenen, H. (1987). Interleukin-1 regulates synthesis of nerve growth factor in non-neuronal cells of the rat sciatic nerve. Nature $330,658-659$.

Lindsay, R. M., and Harmar, A. J. (1989). Nerve growth factor regulates expression of neuropeptide genes in adult sensory neurons. Nature 337 , 362-367.

Maier, S. F., and Watkins, L. R. (1999). Bidirectional communication between the brain and the immune system: implications for behaviour. Anim. Behav. 57, 741-751.

Malley, S. E., and Vizzard, M. A. (2002). Changes in urinary bladder cytokine mRNA and protein after cyclophosphamide-induced cystitis. Physiol. Genomics 9, 5-13.

Ness, T. J. (2005). Pelvic pain in women and men: recent findings. Curr. Opin. Anaesthesiol. 18, 555-562.

Neuhaus, J., Schlichting, N., Oberbach, A., and Stolzenburg, J. U. (2007). Lipopolysaccharide-mediated regulation of interleukin-6 in cultured human detrusor smooth muscle cells. Urologe A 46, 1193-1197.

Nishii, H., Nomura, M., Fujimoto, N., and Matsumoto, T. (2006). Up-regulation of interleukin- 6 gene expression in cyclophosphamide-induced cystitis in mice: an in situ hybridization histochemical study. Int. J. Urol. 13, 1339-1343.

Parkin, J., and Cohen, B. (2001). An overview of the immune system. Lancet 357, 1777-1789.

Patterson, P. H. (1994). Leukemia inhibitory factor, a cytokine at the interface between neurobiology and immunol- ogy. Proc. Natl. Acad. Sci. U.S.A. 91, 7833-7835.

Peeker, R., Enerback, L., Fall, M., and Aldenborg, F. (2000). Recruitment, distribution and phenotypes of mast cells in interstitial cystitis. J. Urol. 163, 1009-1015.

Petrone, R. L., Agha, A. H., Roy, J. B., and Hurst, R. E. (1995). Urodynamic findings in patients with interstitial cystitis. J. Urol. 153, 290A.

Poole, S., de Queiroz Cunha, F., and Henriques Ferreira, S. (1998). "Hyperalgesia from subcutaneous cytokines," in Cytokines and Pain, eds L. R. Watkins and S. F. Maier (Boston: Birkhauser Verlag), 59-88.

Poole, S., and Woolf, C. J. (1998). "Cytokine-nerve growth factor interactions in inflammatory hyperalgesia," in Cytokines and Pain, eds L. R. Watkins and S. F. Maier (Boston: Birkhauser Verlag), 59-88.

Rao, M. S., Sun, Y., Escary, J. L., Perreau, J., Tresser, S., Patterson, P. H., Zigmond, R. E., Brulet, P., and Landis, S. C. (1993). Leukemia inhibitory factor mediates an injury response but not a target-directed developmental transmitter switch in sympathetic neurons. Neuron 11, 1175-1185.

Saban, M. R., Hellmich, H., Nguyen, N. B., Winston, J., Hammond, T. G., and Saban, R. (2001a). Time course of LPSinduced gene expression in a mouse model of genitourinary inflammation. Physiol. Genomics 5, 147-160.

Saban, R., Saban, M. R., Nguyen, N. B., Hammmond, T. G., and Wershil, B. K. (2001b). Mast cell regulation of inflammation and gene expression during antigen-induced bladder inflammation in mice. Physiol. Genomics 10, 35-43.

Saban, R. (2001). Gene-regulation during bladder neurogenic inflammation. Urology 57, 103.

Sairanen, J., Hotakainen, K., Tammela, T. L., Stenman, U. H., and Ruutu, M. (2008). Urinary epidermal growth factor and interleukin-6 levels in patients with painful bladder syndrome/interstitial cystitis treated with cyclosporine or pentosan polysulfate sodium. Urology 71, 630-633.

Sant, G., and Hanno, P. M. (2001). Interstitial cystitis: current issues and controversies in diagnosis. Urology 57,82 .

Sant, G. R., Kempuraj, D., Marchand, J. E., and Theoharides, T.C. (2007). The mast cell in interstitial cystitis: role in pathophysiology and pathogenesis. Urology 69, 34-40.

Studeny, S., Cheppudira, B. P., Meyers, S., Balestreire, E. M., Apodaca, G., Birder, L. A., Braas, K. M., Waschek, J.A., May, V., and Vizzard, M. A. (2008). Urinary bladder function and somatic sensitiv- ity in vasoactive intestinal polypeptide (VIP)-I- mice. J. Mol. Neurosci. 36, 175-187.

Sugiura, S., Lahav, R., Han, J., Kou, S. Y., Banner, L. R., de Pablo, F., and Patterson, P. H. (2000). Leukaemia inhibitory factor is required for normal inflammatory responses to injury in the peripheral and central nervous systems in vivo and is chemotactic for macrophages in vitro. Eur. J. Neurosci. 12, 457-466.

Sun, Y., and Zigmond, R. E. (1996a). Involvement of leukemia inhibitory factor in the increases in galanin and vasoactive intestinal peptide mRNA and the decreases in neuropeptide $Y$ and tyrosine hydroxylase mRNA in sympathetic neurons after axotomy. J. Neurochem. 67, 1751-1760.

Sun, Y., and Zigmond, R. E. (1996b). Leukaemia inhibitory factor induced in the sciatic nerve after axotomy is involved in the induction of galanin in sensory neurons. Eur. J. Neurosci. 8, 2213-2220.

Thompson, S. W., Priestley, J. V., and Southall, A. (1998). gp130 cytokines, leukemia inhibitory factor and interleukin-6, induce neuropeptide expression in intact adult rat sensory neurons in vivo: time-course, specificity and comparison with sciatic nerve axotomy. Neuroscience 84, 1247-1255.

Ulich, T. R., Fann, M. J., Patterson, P. H., Williams, J.H., Samal, B., Del Castillo, J., Yin, S., Guo, K., and Remick, D. G. (1994). Intratracheal injection of LPS and cytokines. V. LPS induces expression of LIF and LIF inhibits acute inflammation. Am. J. Physiol. 267, L442-L446.

Vizzard, M. A. (1997). Increased expression of neuronal nitric oxide synthase in bladder afferent and spinal neurons following spinal cord injury. Dev. Neurosci. 19, 232-246.

Vizzard, M. A. (2000a). Alterations in spinal Fos protein expression induced by bladder stimulation following cystitis. Am. J. Physiol. 278, R1027-R1039.

Vizzard, M. A. (2000b). Changes in urinary bladder neurotrophic factor mRNA and NGF protein following urinary bladder dysfunction. Exp. Neurol. 161, 273-284.

Vizzard, M. A. (2000c). Up-regulation of pituitary adenylate cyclase-activating polypeptide in urinary bladder pathways after chronic cystitis. J. Comp. Neurol. 420, 335-348.

Vizzard, M. A. (2001). Alterations in neuropeptide expression in lumbosacral bladder pathways following chronic cystitis. J. Chem. Neuroanat. 21, 125-138.

Woolf, C. J., Allchorne, A., SafiehGarabedian, B., and Poole, S. (1997). Cytokines, nerve growth factor and inflammatory hyperalgesia: the contribution of tumour necrosis factor. Br. J. Pharmacol. 121, 417-424.

Woolf, C. J., and Doubell, T. P. (1994). The pathophysiology of chronic painincreased sensitivity to low threshold A-beta fiber inputs. Curr. Opin. Neurobiol. 4, 525-534.

Yoshimura, N., and de Groat, W.C. (1999). Increased excitability of afferent neurons innervating rat urinary bladder following chronic bladder inflammation. J. Neurosci. 19, 4644-4653.

Yuridullah, R., Corrow, K. A., Malley, S. E., and Vizzard, M. A. (2006) Expression of fractalkine and fractalkine receptor in urinary bladder after cyclophosphamide (CYP)induced cystitis. Auton. Neurosci. 126-127, 380-389.

Zigmond, R.E., Hyatt-Sachs, H., Mohney, R. P., Schreiber, R. C., Shadiack, A. M. Sun, Y., and Vaccariello, S. A. (1996). Changes in neuropeptide phenotype after axotomy of adult peripheral neurons and the role of leukemia inhibitory factor. Perspect. Dev. Neurobiol. 4, 75-90.

Zvarova, K., and Vizzard, M. A. (2005). Cocaine- and amphetamine-regulated transcript peptide (CARTp) expressing cells in the urinary bladder: a developmental study. J. Comp. Neurol. 475, 590-603.

Zvarova, K., and Vizzard, M. A. (2006). Changes in galanin immunoreactivity in rat micturition reflex pathways after cyclophosphamide-induced cystitis. Cell Tissue Res. 324, 213-224.

Conflict of Interest Statement: The authors declare that the research was conducted in the absence of any commercial or financial relationships that could be construed as a potential conflict of interest.

Received: 29 October 2010; accepted: 09 February 2011; published online: 22 February 2011.

Citation: Girard BM, Cheppudira BP, Malley SE, Schutz KC, May V and Vizzard MA (2011) Increased expression of interleukin-6 family members and receptors in urinary bladder with cyclophosphamideinduced bladder inflammation in female rats. Front. Neurosci. 5:20. doi: 10.3389/ fnins.2011.00020

This article was submitted to Frontiers in Autonomic Neuroscience, a specialty of Frontiers in Neuroscience.

Copyright $\odot 2011$ Girard, Cheppudira, Malley, Schutz, May and Vizzard. This is an open-access article subject to an exclusive license agreement between the authors and Frontiers Media SA, which permits unrestricted use, distribution, and reproduction in any medium, provided the original authors and source are credited. 